\title{
Nanoparticles of a New Small-Molecule P-Selectin Inhibitor Attenuate Thrombosis, Inflammation, and Tumor Growth in Two Animal Models
}

\author{
Qiqi Feng \\ Mengyang Wang \\ Eldar Muhtar (D) \\ Yaonan Wang \\ Haimei Zhu (D)
}

School of Pharmaceutical Sciences, Beijing Area Major Laboratory of Peptide and Small Molecular Drugs, Engineering Research Center of Endogenous Prophylactic of Ministry of Education of China, Capital Medical University, Beijing, 100069, People's Republic of China
Correspondence: Haimei Zhu School of Pharmaceutical Sciences, Capital Medical University, 10 Youanmenwaixitoutiao, Fengtai District, Beijing 100069, People's Republic of China $\mathrm{Tel} / \mathrm{Fax}+86-10-839|-187|$

Email hmzhu@ccmu.edu.cn
Purpose: To assess whether the newly designed small-molecule oral P-selectin inhibitor $3 S$-1,2,3,4-tetrahydro- $\beta$-carboline-3-methyl aspartyl ester (THCMA) as a nanomedicine enhances antithrombosis, anti-inflammation, and antitumor activity more than the clinical trial drug PSI-697.

Methods: THCMA was designed as an amphiphile containing pharmacophores of PSI-697. Its nanofeatures were explored with TEM, SEM, Tyndall effect, $\zeta$-potential, FT-ICR-MS, and NOESY 2D ${ }^{1} \mathrm{H}$ NMR. The P-selectin inhibitory effect of THCMA was demonstrated with molecular docking, ultraviolet (UV) spectra, and competitive ELISA. In vivo and in vitro assays - anti-arterial thrombosis, anti-venous thrombosis, anti-inflammation, antitumor growth, anti-platelet aggregation, rat-tail bleeding time, anticoagulation index, soluble P-selectin (sP-selectin) expression, and serum TNF $\alpha$ expression - were performed to explore bioactivity and potential mechanisms. Water solubility of THCMA was measured using UV-absorption spectra.

Results: THCMA self-assembled into nanorings of approximately $100 \mathrm{~nm}$ in diameter. Its water solubility was about 1,030-fold that of PSI-697. THCMA exhibited more potent P-selectin inhibitory effect than PSI-697. The oral efficacy of THCMA was 100-fold that of PSI-697 in inhibiting arterial and venous thrombosis and tenfold in inhibiting inflammation. THCMA inhibited thrombosis at a dose that produces no coagulation disorders and no bleeding risk. THCMA exhibited enhanced antitumor activity over PSI-697 without systemic chemotherapy toxicity. THCMA significantly inhibited platelet aggregation in vitro and downregulated the expression levels of serum sP-selectin and TNF $\alpha$ in vivo.

Conclusion: A new small-molecule P-selectin inhibitor, THCMA, has been successfully designed as a nanomedicine with largely enhanced oral efficacy compared to the clinical trial drug PSI-697, and thus might be developed for the oral treatment of arterial thrombosis, venous thrombosis, inflammation, and cancer-associated thrombosis.

Keywords: P-selectin, thrombosis, inflammation, cancer, antagonist, self-assembly

\section{Introduction}

P-selectin is an integral membrane protein expressed on activated platelet surfaces and endothelial cell surfaces. ${ }^{1}$ Its overexpression occurs not only on the vascular endothelium of tumors but also on lung, ovarian, lymphoma, and breast cancer cells. ${ }^{2}$ As an adhesion molecule, P-selectin binds with P-selectin glycoprotein ligand 1 (PSGL1), the cognate ligand expressed on leukocytes, T cells, and myeloid, lymphoid, carcinoma, and dendritic cells. ${ }^{3,4}$ This binding mediates the adhesion of platelets, leukocytes, T cells, endothelial cells, and tumor cells, 
resulting in inflammation, thrombosis and tumor growth and metastasis. It is evident that inhibiting the binding between P-selectin and PSGL1 sheds light on drug development for treating inflammation, ${ }^{5}$ arterial thrombosis, ${ }^{6}$ venous thrombosis, ${ }^{7}$ tumor growth, ${ }^{8}$ tumor metastasis, ${ }^{8}$ and cancer-associated thrombosis. ${ }^{9-11}$

Currently, drugs designed for this purpose mainly fall into three types: monoclonal antibodies, including inclacumab $^{12}$ and crizanlizumab, ${ }^{13}$ glycosulfopeptides mimicking truncated N-terminal PSGL1 monomers like GSnP-6, ${ }^{14}$ and small-molecule inhibitors, such as GMI$1070,{ }^{15}$ bimosiamose (TBC1269), ${ }^{16}$ and PSI-697. ${ }^{17}$ Those drugs, however, are far from satisfying for clinical use. The first two types are considered inadequate to fulfill daily or long-term therapeutic needs. For example, crizanlizumab, the first FDA-approved P-selectin inhibitor for sickle-cell treatment, ${ }^{18}$ has the limitations of high manufacturing costs, short shelf life, and intravenous administration. Similarly, GSnP-6 also needs administration through the jugular cannula. ${ }^{14}$ The complicated synthesis of GSnP-6 involves multiple chemical and enzymatic steps, making it hard to be manufactured. As for the third type, most of the small-molecule P-selectin inhibitors designed as sialyl Lewis ${ }^{\mathrm{X}}$ (sLeX) mimetics have been shown to be therapeutically ineffective because of their low binding affinity to P-selectin. For instance, the potency of $\mathrm{P}$-selectin for the glycomimetic P-selectin inhibitors GMI-1070 and TBC1269 is $\mathrm{K}_{\mathrm{d}} 200 \mu \mathrm{M}$ and $\mathrm{IC}_{50} 70$ $\mu \mathrm{M}$, respectively. ${ }^{19}$ GMI-1070 and TBC1269 are also administered by intravenous injection or by inhalation.

In contrast, PSI-697 is the only orally effective P-selectin inhibitor in clinical trials. Although it is also limited by its low potency for P-selectin $(\mathrm{Kd} 200 \mu \mathrm{M})$, it is not a sLeX-mimicking small molecule and is able to reduce inflammation and thrombosis in animal models. ${ }^{20,21}$ One negative result for PSI-697 as an antithrombotic drug is that it did not prevent platelet-monocyte aggregation in a phase I trial in healthy smokers, possibly because of the low tested dose and water solubility. ${ }^{17}$ The low blocking activity and poor solubility of PSI-697 might be causes of high dose requirements. Nevertheless, PSI697 is still a significant start for further exploration of oral P-selectin inhibitors.

Detailed analyses of the interactions between P-selectin and PSGL1 have revealed that high-affinity binding between P-selectin and PSGL1 attributes to the three sulfated tyrosines Tys46, Tys48, and Tys51 and sLeX oligosaccharide at threonine 57 (Figure 1A). ${ }^{14,22-24}$ Tys48 has been suggested to make a larger contribution to the binding than Tys46 and Tys51. ${ }^{14}$ Therefore, the binding site of Tys 48 to P-selectin could be a potential drug-design site.

We aimed to design a molecule with a binding mode similar to PSI-697 to P-selectin, but with enhanced solubility and activity. To begin with, we docked PSI-697 and its derivative PSI- $421^{25}$ to the crystal structure of P-selectin (PDB code 1G1S), finding that they both blocked the interaction of Tys48 of PSGL1 with P-selectin (Figure 1B). Moreover, what we have previously tested showed that 1,2,3,4-tetrahydro- $\beta$-carboline (THC) derivatives interacted with P-selectin at the Tys48 binding site and downregulated the expression of $\mathrm{sP}$ selectin. $^{26-29}$ Therefore, we took THC as a template and designed 3S-THC-3-methyl aspartyl ester (THCMA) as a new small-molecule oral P-selectin inhibitor. THCMA contains two important pharmacophores of PSI-697 that are connected with a linker to produce an amphiphilic molecule. THCMA significantly improved the $\log \mathrm{P}$ $(-2.21)$ and $\log \mathrm{S}(1.11)$ values versus the $\log \mathrm{P}(5.88)$ and $\log \mathrm{S}(-4.74)$ values of PSI-697, indicating significantly improved solubility and pharmacokinetic properties (Figure 1C). For the docking results (Figure 1D), the binding site of the carboline moiety of THCMA matched with the modified quinoline moiety of PSI-697 well. Similarly to the functional carboxylate group of PSI-697, the carboxylate group of THCMA interacted with Lys 112 of P-selectin. The docked binding free energy of THCMA $(-7.45 \mathrm{kcal} / \mathrm{mol})$ was lower than PSI-697 $(-7.30 \mathrm{kcal} /$ mol). We hence hypothesized that THCMA as a new small-molecule oral P-selectin inhibitor would effectively inhibit P-selectin-mediated events, particularly those observed in thrombosis, inflammation, and tumor growth.

\section{Methods}

Boc-D(OBzl)-OH has an L configuration. PSI-697 was purchased from MedChemExpress (Monmouth Junction, NJ, USA). HPLC, melting points (MPs), ${ }^{1} \mathrm{H}$ and ${ }^{13} \mathrm{C}$ nuclear magnetic resonance (NMR) spectra, electrospray ionization mass spectrometry (ESI-MS), ESI $( \pm)$-ICR -FT-MS spectrum, optical rotations, and ultraviolet (UV) absorption spectrum were assessed using similar methods to the literature. ${ }^{30,31}$ The purchase and maintenance of animals used in in vivo assays and the statistical analyses of all biological data were performed in a similar way to the literature. ${ }^{31,32}$ 

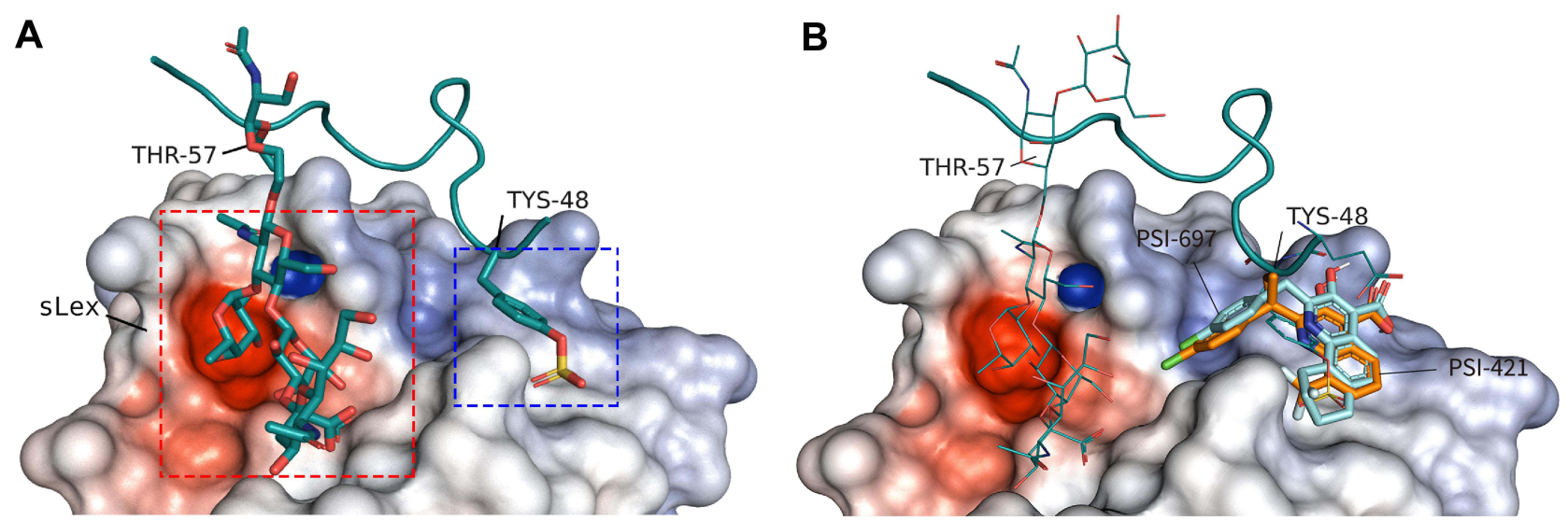

C

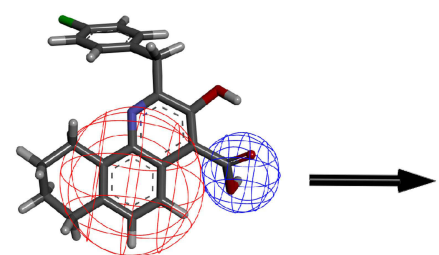

PSI-697

LogP 5.88

LogS -4.74

D

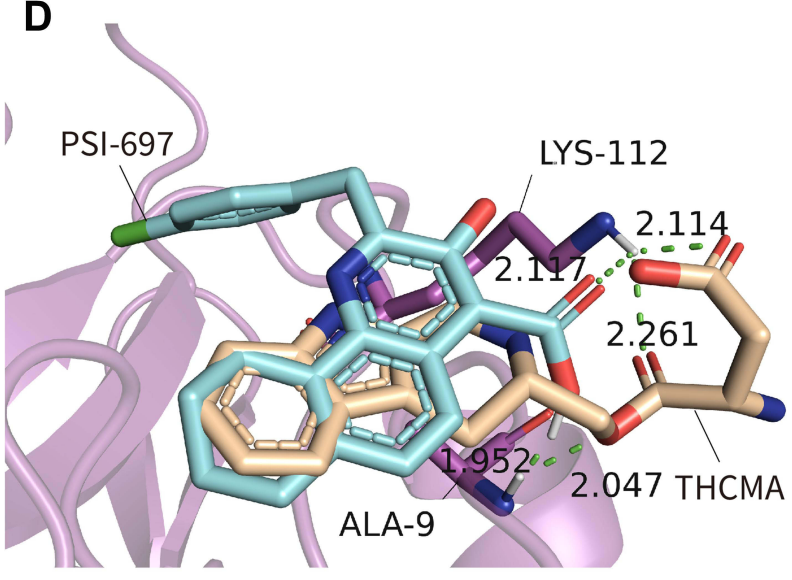

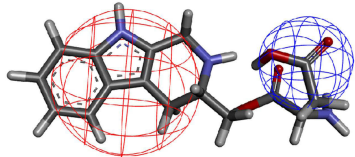

THCMA

LogP -2.21

LogS 1.11

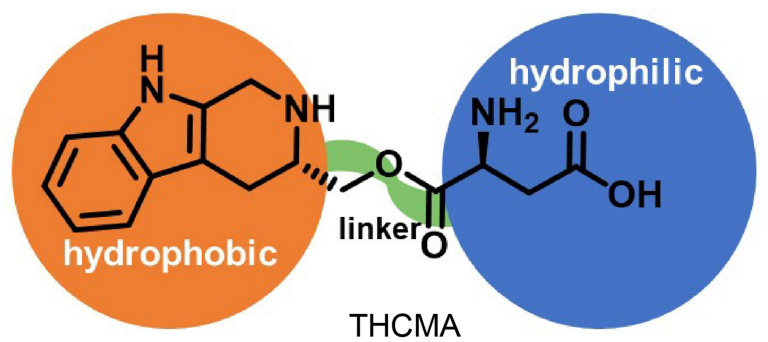

3S-1,2,3,4-tetrahydro- $\beta$-carboline-3-methyl aspartyl ester

\section{Interactions \\ Pi-Cation}

$\square$ Conventional Hydrogen Bond $\square$ Pi-Alkyl
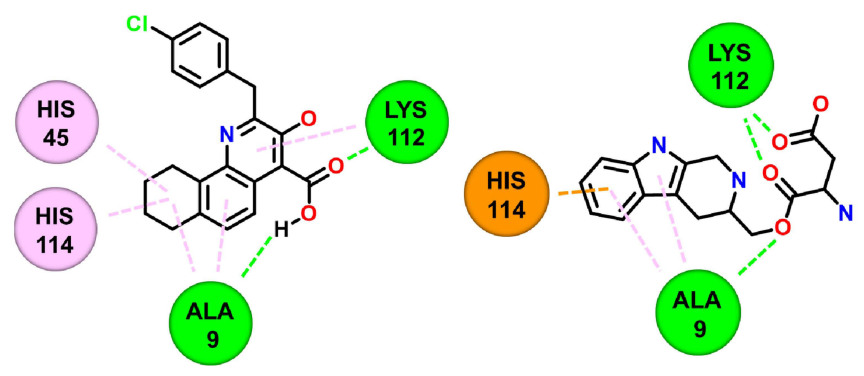

THCMA

PSI-697

Binding energy: $-7.30 \mathrm{kcal} / \mathrm{mol}$ Binding energy: $-7.45 \mathrm{kcal} / \mathrm{mol}$

Figure I Rational structure design of THCMA. (A) Two regions involved in the interactions between P-selectin (surface model) and PSGLI (ribbon model), sLeX moiety (stick model) and sulfated tyrosine Tys48 (stick model). (B) PSI-697 (cyan stick model) and PSI-42I (orange stick model) binding at the PSGLI Tys48 binding site of P-selectin (surface model). (C) THCMA structurally designed by connecting two pharmacophores of PSI-697 with a linker to produce an amphiphilic molecule for improved solubility ( $\log S$ ) and bioavailability (logP). (D) Molecular interactions and binding energies between P-selectin (ribbon model) and PSI-697 (cyan stick model) and THCMA (wheat stick model), with detailed interactions presented in 2-D. Figures rendered with PDB IGIS and docking results and plotted with PyMol and APBS plugins. ${ }^{44}$

Male Sprague Dawley rats and male ICR mice were purchased from the Laboratory Animal Center of Capital Medical University. Ethics and legal approval from the Ethics Committee of Capital Medical University was obtained prior to commencement of all evaluations. Animal welfare was maintained in accordance with the requirements of Animal Welfare Act and the NIH Guide for the Care and Use of Laboratory Animals, and approved by Ethics Committee of Capital Medical University.

\section{Energy Minimization of THCMA Conformation}

The conformation of THCMA was energy-minimized with Discovery Studio 2017 following methods in the literature. ${ }^{32}$ The THCMA conformation with the lowest energy was docked to the active site of P-selectin and adopted for the construction of self-assembled nanoparticles.

\section{Molecular Docking}

To investigate the binding modes of THCMA, PSI-697, and PSI-421 with P-selectin, molecular docking studies 
were carried following methods in the literature. ${ }^{32}$ The protein (chain A of PDB 1G1S) was used as the rigid receptor. The size of the grid box was $80 \times 80 \times 80 \AA$, covering the interaction surface of the ligand in the crystal structure 1G1S. Energy-minimized THCMA, PSI-697, and PSI-421 were treated as flexible ligands.

\section{Synthesis of 3S-THC-3-Carboxylic Acid (I)}

L-Trp $5 \mathrm{~g}$ and $25 \mathrm{~mL} 1 \mathrm{M} \mathrm{H}_{2} \mathrm{SO}_{4}$ were added to $80 \mathrm{~mL}$ water. Formaldehyde ( $8 \mathrm{~mL}, 36-38 \%)$ was then added to react for 2 hours at room temperature. The $\mathrm{pH}$ of the mixture was adjusted to 7 with ammonia liquor. Precipitates were filtered after 12 hours' storage at $0^{\circ}$ C. After recrystallization, $3.97 \mathrm{~g}$ of 1 (yield $75 \%$ ) was obtained as colorless powder. ESI/MS:217[M+H] $]^{+}$.

Synthesis of 3S-THC-3-Carboxylic Acid Methyl Ester (2) Thionyl chloride $3 \mathrm{~mL}$ was slowly added to $40 \mathrm{~mL}$ of methanol at $0^{\circ} \mathrm{C}$. After 40 minutes $3 \mathrm{~g}$ of 1 was added to react at room temperature. TLC $\left(\mathrm{CH}_{2} \mathrm{Cl}_{2} / \mathrm{CH}_{3} \mathrm{OH}, 30 / 1\right)$ was used to determine the reaction endpoint. After vacuum evaporation, $30 \mathrm{~mL}$ ethyl acetate was added to dissolve the residue. The ethyl acetate solution was washed three times with saturated $\mathrm{NaHCO}_{3}$, then three times with saturated $\mathrm{NaCl}$ and dried with anhydrous $\mathrm{Na}_{2} \mathrm{SO}_{4}$. After vacuum evaporation, the residue was purified with chromatography $\left(\mathrm{CH}_{2} \mathrm{Cl}_{2} / \mathrm{CH}_{3} \mathrm{OH}, 40 / 1\right)$ to obtain $1.7 \mathrm{~g}$ of 2 (yield $54 \%$ ) as colorless powder. ESI/MS:231.1[M+H $]^{+}$.

\section{Synthesis of 3S-THC-3-Methanol (3)}

$\mathrm{LiAlH}_{4} 0.7 \mathrm{~g}$ was added slowly to $60 \mathrm{~mL}$ of anhydrous THF at $0^{\circ} \mathrm{C}$. After that $1 \mathrm{~g}$ of 2 was added and reacted for 5 hours. TLC $\left(\mathrm{CH}_{2} \mathrm{Cl}_{2} / \mathrm{CH}_{3} \mathrm{OH}, 10 / 1\right)$ was used to determine the reaction end point. $\mathrm{H}_{2} \mathrm{O} 0.7 \mathrm{~mL}, 1.5 \mathrm{~mL} 4 \mathrm{~N}$ $\mathrm{NaOH}$, and $1 \mathrm{~mL} \mathrm{H}_{2} \mathrm{O}$ were added dropwise in sequence and stirred for 40 minutes. The filtered liquor was vacuumevaporated. Chromatography $\left(\mathrm{CH}_{2} \mathrm{Cl}_{2} / \mathrm{CH}_{3} \mathrm{OH}, 10 / 1\right)$ was used to purify the residue to obtain $0.63 \mathrm{~g}$ (yield $72 \%$ ) of 3 as colorless powder. ESI/MS:203.2 $[\mathrm{M}+\mathrm{H}]^{+}$.

\section{Synthesis of 3S-N-Boc-THC-3-Methanol (4)}

(Boc) ${ }_{2} \mathrm{O} 1.4 \mathrm{~g}$ and $1 \mathrm{~g}$ of 3 were mixed in $40 \mathrm{~mL}$ anhydrous THF. The $\mathrm{pH}$ of the solution was adjusted to 9 with NMM. The reaction was vacuumed and monitored to remain at $\mathrm{pH} 9$ at room temperature. TLC $\left(\mathrm{CH}_{2} \mathrm{Cl}_{2} / \mathrm{CH}_{3}\right.$ $\mathrm{OH}, 30 / 1)$ was used to determine the end point of the reaction. After vacuum evaporation, $50 \mathrm{~mL}$ ethyl acetate was used to dissolve the residue. The ethyl acetate solution was washed three times with 5\% KHSO4 and then three times with saturated $\mathrm{NaCl}$ and dried with anhydrous $\mathrm{Na}_{2}$ $\mathrm{SO}_{4}$. After vacuum evaporation, chromatography $\left(\mathrm{CH}_{2} \mathrm{Cl}_{2}\right.$ $\left./ \mathrm{CH}_{3} \mathrm{OH}, 120 / 1\right)$ was used to purify the residue to get 1.34 $\mathrm{g}$ of 4 (yield 90\%) as colorless powder. ESI/MS:303.2 $[\mathrm{M}+\mathrm{H}]^{+}$.

\section{Synthesis of 3S-N-Boc-THC-3-Methyl-(Boc) Aspartyl Ester-OBzl (5)}

Boc-D(OBzl)-OH 0.84 g, 0.41 g DCC, and 24 mg DMAP were mixed in $40 \mathrm{~mL}$ anhydrous THF at $0^{\circ} \mathrm{C}$ for 40 minutes. Then, $0.6 \mathrm{~g}$ of 4 was added to react until the end point indicated by TLC $\left(\mathrm{CH}_{2} \mathrm{Cl}_{2} / \mathrm{CH}_{3} \mathrm{OH}, 30 / 1\right)$ had been reached. Ethyl acetate $50 \mathrm{~mL}$ was used to dissolve the residue obtained after evaporation. The solution was washed with saturated $\mathrm{NaHCO}_{3}$, saturated $\mathrm{NaCl}, 5 \% \mathrm{KHSO}_{4}$, saturated $\mathrm{NaCl}$, saturated $\mathrm{NaHCO}_{3}$, and saturated $\mathrm{NaCl}$ three times each and dried with anhydrous $\mathrm{Na}_{2} \mathrm{SO}_{4}$. Chromatography (PE/EA, 4/1) was used to purify the residue obtain after vacuum evaporation to provide $0.9 \mathrm{~g}$ of 5 (yield $74 \%$ ) as colorless powder. ESI/MS:608.3[M+H $]^{+}$.

\section{Synthesis of 3S-N-Boc-THC-3-Methyl-(Boc) Aspartyl} Ester (6)

At $0^{\circ} \mathrm{C}$, hydrogen gas was aerated into a suspension of 0.5 $\mathrm{g}$ of $5,0.1 \mathrm{~g} \mathrm{Pd} / \mathrm{C}$ and $30 \mathrm{~mL}$ methanol for 6 hours, and TLC $\left(\mathrm{CH}_{2} \mathrm{Cl}_{2} / \mathrm{CH}_{3} \mathrm{OH}, 30 / 1\right)$ was used to determine the reaction end point. Filtrates of the reaction mixture were evaporated to provide $0.42 \mathrm{~g}$ of 6 (yield 95\%) as lightyellow powder. ESI/MS:518.3[M+H] $]^{+}$.

\section{Synthesis of 3S-THC-3-Methyl Aspartyl Ester (THCMA)}

Hydrogen chloride $50 \mathrm{~mL}$ in $4 \mathrm{M}$ anhydrous ethyl acetate was added to $0.4 \mathrm{~g}$ of 6 and reacted for 5 hours at $0^{\circ}$ C. TLC $\left(\mathrm{EA} / \mathrm{H}_{2} \mathrm{O} / \mathrm{CH}_{3} \mathrm{COOH}, 3 / 1 / 1\right)$ was used to show complete disappearance of 6 . After vacuum evaporation, the residue was dissolved in ethyl acetate and anhydrous ether and evaporated to remove hydrogen chloride three times to provide $0.28 \mathrm{~g}$ of yellow powder. The powder was purified with a reverse-phase $\mathrm{C}_{18}$ column $\left(\mathrm{H}_{2} \mathrm{O}\right.$ / $\mathrm{MeOH}, 2 / 1)$, evaporated, and freeze-dried to provide $0.13 \mathrm{~g}$ THCMA (yield $48 \%$ ) as white powders $\mathrm{Mp}$ $203.5^{\circ} \mathrm{C}-208.2^{\circ} \mathrm{C} ; \quad[\alpha]_{D}^{25}:+14.03 \quad\left(\mathrm{c}=0.100, \mathrm{CH}_{3} \mathrm{OH}\right)$; ${ }^{1} \mathrm{H}$ NMR $\left(800 \mathrm{MHz}\right.$, DMSO- $\left.d_{6}\right) \delta 11.11(\mathrm{~s}, 1 H), 7.42$ $(\mathrm{d}, J=7.9 \mathrm{~Hz}, 1 H), 7.37(\mathrm{~d}, J=8.1 \mathrm{~Hz}, 1 H), 7.10(\mathrm{t}$, $J=7.6 \mathrm{~Hz}, 1 H), 7.02(\mathrm{t}, J=7.3 \mathrm{~Hz}, 1 \mathrm{H}), 4.59$ (d, $J=11.9$ $\mathrm{Hz}, 1 H), 4.48(\mathrm{dd}, J=11.9,6.3 \mathrm{~Hz}, 1 H), 4.40(\mathrm{~d}, J=15.4$ $\mathrm{Hz}, 1 H), 4.31(\mathrm{~d}, J=15.4 \mathrm{~Hz}, 1 H), 4.27(\mathrm{~m}, 1 H), 3.81(\mathrm{~m}$, 1H), $2.97(\mathrm{~m}, 2 \mathrm{H}), 2.87(\mathrm{dd}, J=16.9,7.3 \mathrm{~Hz}, 2 \mathrm{H}), 2.45$ 
$(\mathrm{s}, 1 \mathrm{H}) .{ }^{13} \mathrm{C}$ NMR $\left(75 \mathrm{MHz}, \mathrm{DMSO}-d_{6}\right) \delta 170.08,136.64$, $128.08,126.55,121.97,121.84,119.35,111.78,105.49$, $65.15,52.65,50.26,40.56,39.17$, and 21.65. HPLC purity $99.5 \%$. ESI ${ }^{+}$-FT-ICR-MS (m/z): $318.14725[\mathrm{M}+\mathrm{H}]^{+}$.

\section{Self-Assembly of THCMA FT-ICR-MS and qCID Spectra}

Positive electrospray ionization (ESI) was used to record the FT-ICR-MS spectrum of THCMA. The qCID spectrum of $1,269.56151 \mathrm{~m} / \mathrm{z}$ was isolated for further analysis. Spectral data were analyzed with the instrument's software.

\section{NOESY 2D 'H NMR Spectrum}

The NOESY 2D ${ }^{1} \mathrm{H}$ NMR spectrum of THCMA was measured following the instructions for an $800 \mathrm{MHz}$ Bruker spectrometer.

\section{TEM and SEM}

The morphology and size of nanoparticles in $0.1 \mu \mathrm{M}$ THCMA water solution at $\mathrm{pH} 7$ and lyophilized powder were observed as per the literature. ${ }^{33}$

\section{Particle Size and $\zeta$-Potential}

Nanofeatures of various concentrations of THCMA water solution $(10 \mu \mathrm{M}, 1 \mu \mathrm{M}, 0.1 \mu \mathrm{M}$, and $0.01 \mu \mathrm{M})$ at both $\mathrm{pH}$ 7 and $\mathrm{pH} 2$ were identified. The Tyndall effect of the solutions was excited with a $650 \mathrm{~nm}$ laser. Particle-size fluctuation in 7 days and $\zeta$-potential of the solutions were recorded as per the literature. ${ }^{31}$

\section{Direct Interaction Between THCMA and P-Selectin \\ Influence of THCMA on UV Spectra of P-Selectin}

To define the direct interaction between THCMA and P-selectin, the influence of increasing amounts of THCMA (final concentration 2-40 $\mu \mathrm{M}, \mathrm{pH} 7.4$ ), PSI-697 (final concentration 2-40 $\mu \mathrm{M}, \mathrm{pH}$ 7.4), THCMA:PSI-697 1:1 (total final concentration 2-40 $\mu \mathrm{M}, \mathrm{pH} 7.4$ ), and THCMA:PSI-697 1:3, total final concentration 2-80 $\mu \mathrm{M}$, $\mathrm{pH}$ 7.4) on the UV spectra of P-selectin was monitored at a wavelength of $280 \mathrm{~nm}$ using methods described in the literature. $^{32}$

\section{Competitive Binding Assay of THCMA with P-Selectin Against PSGLI on HL60}

The competitive binding assay was modified from a method described in the literature. ${ }^{34}$ Rat antimouse IgG antibody (20 $\mathrm{ng} / \mathrm{mL}, 50 \mu \mathrm{L}$ ) was coated onto microtiter plates overnight at $4^{\circ} \mathrm{C}$. The plates were washed and blocked for 8 hours at $4^{\circ}$ $\mathrm{C}$ with $3 \% \mathrm{BSA}$. To each well, $50 \mu \mathrm{L}$ human recombinant P-selectin- $\mathrm{IgG}$ chimera protein (200 ng/mL, R\&D Systems) was added. The plates were carefully washed three times, and to each well HL60 cells (1,000 cells/well, $100 \mu \mathrm{L})$ with NS, PSI-697 $(25 \mu \mathrm{M})$, and THCMA ( 25 and $100 \mu \mathrm{M})$ were added and allowed to adhere in the presence or absence of compounds for 30 minutes at $37^{\circ} \mathrm{C}$. PSI- 697 was used as positive control. The plates were placed upside down on centrifuge (1,000 rpm, 3 minutes) to remove nonadherent cells. Adherent cells were quantified by counting the cell numbers under microscopy. The activity of the inhibitors is presented as adherent percentage: (adherent cell numbers in experimental group - aspecific adherent cell numbers) $\div$ (adherent cell numbers in blank group - aspecific adherent cell numbers) $\times 100 \%$. Each experiment had six replicates and was statistically analyzed using a $t$-test.

\section{Antiplatelet Assays}

Antiplatelet Activity of THCMA Observed on AFM Interactions between THCMA and platelets and the effect of THCMA on the aggregation of platelets were observed with AFM of platelets in the presence and absence of THCMA. The images were captured as per the literature. ${ }^{32}$ The morphology of platelets at resting state, AA activated state in NS, and AA activated state in the presence of various concentrations of THCMA (final concentrations $10^{-5}, 10^{-6}$, and $10^{-7} \mathrm{M}$ ) were observed.

\section{Anti-Platelet Aggregation Assay of THCMA}

To determine the inhibitory effect of THCMA and PSI-697 on the aggregation of platelets, an in vitro plateletaggregation assay was performed as per the literature. ${ }^{31}$

\section{THCMA Bioassays}

\section{Arterial Thrombus Weight}

To evaluate the in vivo anti-arterial thrombosis activity of THCMA, a rat arteriovenous shunt silk-thread model described in the literature was used. ${ }^{31} \mathrm{CMCNa}(0.5 \%$, $3 \mathrm{~mL} / \mathrm{kg}$ ) was given orally to the negative-control group. Aspirin $167 \mu \mathrm{mol} / \mathrm{kg}$ was given orally to the positivecontrol group. PSI-697 $5 \mu \mathrm{mol} / \mathrm{kg}$ was given orally to the positive-control group of the P-selectin inhibitor. The three test groups were given $5,0.5$, and $0.05 \mu \mathrm{mol} / \mathrm{kg}$ THCMA orally. 


\section{Venous Thrombus Weight}

To evaluate the in vivo anti-venous thrombosis activity of THCMA, a rat inferior vena cava (IVC) ligation model from the literature was adopted. ${ }^{35}$ The negative-control group was given $3 \mathrm{~mL} / \mathrm{kg} 0.5 \% \mathrm{CMCNa}$ orally. The positive-control group was given $4.87 \mu \mathrm{mol} / \mathrm{kg}$ warfarin orally. The P-selectin inhibitor positive-control group was given 5 $\mu \mathrm{mol} / \mathrm{kg}$ of PSI-697 orally. THCMA 5, 0.5, and 0.05 $\mu \mathrm{mol} / \mathrm{kg}$ were given orally to the three test groups.

\section{Anti-Inflammation}

To evaluate the in vivo anti-inflammation activity of THCMA, a xylene-induced ear-edema mouse model was used as per the literature. ${ }^{36}$ For the negative-control group, a single dose of $10 \mathrm{~mL} / \mathrm{kg} 0.5 \% \mathrm{CMCNa}$ was given. For the positive-control group, a single dose of $1,110 \mu \mathrm{mol} / \mathrm{kg}$ aspirin was given. For the three test groups, a single dose of $5,0.5$, and $0.05 \mu \mathrm{mol} / \mathrm{kg}$ THCMA was given.

\section{Antitumor}

P-selectin is involved in both tumor growth and metastasis. ${ }^{8,37}$ To evaluate the in vivo antitumor activity of THCMA, a nonmetastatic S180 mouse model was adopted as per the literature. ${ }^{32}$ Mice in the assay were given drugs orally for 10 consecutive days and then killed with diethyl ether anesthesia. $\mathrm{CMCNa} 0.5 \%$ was given orally to the mice in the negative-control group. Doxorubicin (Dox) $5 \mu \mathrm{mol} / \mathrm{kg} / \mathrm{day}$ was adminstered intraperitoneally to the mice in positive control group, $5 \mu \mathrm{mol} / \mathrm{kg} /$ day PSI-697 was given orally to those in the P-selectin inhibitor positive-control group, and 5 $\mu \mathrm{mol} / \mathrm{kg} /$ day THCMA was given orally to the mice in the test group. The body weights of all mice were recorded every day. After death, $1 \mathrm{~mL}$ fresh blood was collected for each mouse and tumors and organs dissected and weighed immediately.

\section{Rat Tail-Bleeding Time}

This assay was performed using a method mentioned in the literature. ${ }^{38}$ In our assay, the rats in the negativecontrol group were given $3 \mathrm{~mL} / \mathrm{kg} 0.5 \% \mathrm{CMCNa}$ orally, those in the positive-control group $4.87 \mu \mathrm{mol} / \mathrm{kg}$ warfarin orally, the P-selectin inhibitor positive-control group 5 $\mu \mathrm{mol} / \mathrm{kg}$ of PSI- 697 orally, and the test group $5 \mu \mathrm{mol} / \mathrm{kg}$ of THCMA orally.

\section{PT, TT, APTT, and Fib}

Activated partial thromboplastin time (APTT), thrombin time (TT), prothrombin time (PT), and plasma fibrinogen (Fib) were measured in sera of the IVC-ligation rats used in the anti-venous thrombosis assay according to procedures in the literature. ${ }^{30}$

\section{sP-Selectin- and TNF $\alpha$ Expression}

Sera from the anti-inflammation, anti-arterial thrombosis, anti-venous thrombosis, and antitumor assays were collected according to the manufacturer's instructions of rat and mouse ELISA kits. To measure expression levels of P-selectin and TNF $\alpha$ in the serum, the ELISA kits were used as per the literature. ${ }^{32}$

\section{Solubility}

Maximum solubility of THCMA and PSI-697 in water was measured and calculated using standard curves with a Shimadzu UV-2600. Maximum-absorption wavelengths of THCMA and PSI-697 were $362.4 \mathrm{~nm}$ and $196.3 \mathrm{~nm}$, respectively. Absorbance of a series of THCMA solutions $(1,577,789,394,197$, and $99 \mu \mathrm{M})$ and PSI-697 solutions $(54,18,6,2$, and $1 \mu \mathrm{M})$ were measured. Regression equations were plotted in terms of concentration to absorbance. Saturated THCMA and PSI-697 solutions were prepared and UV absorbance measured to calculate maximum solubility.

\section{Results}

\section{THCMA Exhibits Good Solubility in Water}

The poor solubility of PSI-697 might be a cause of the need for high dosage. THCMA was structurally designed as an amphiphilic molecule to improve solubility. The maximum solubility of THCMA and PSI-697 in water was $5,040 \mu \mathrm{M}$ and $4.89 \mu \mathrm{M}$, respectively, THCMA is about 1,030-fold that of PSI-697, which is good for the development of an oral drug.

\section{THCMA is a New Small-Molecule P-Selectin Inhibitor UV-Spectrum Changes in P-Selectin upon Binding of THCMA}

The direct binding interactions of THCMA and PSI-697 with P-selectin were demonstrated with UV spectra in vitro. Figure $2 \mathrm{~A}$ and $\mathrm{C}$ show that $\mathrm{P}$-selectin exhibited absorbance at 280nm, while PSI-697 and THCMA exhibited little absorbance at $280 \mathrm{~nm}$. Figure $2 \mathrm{~B}$ and D show that both PSI-697 and THCMA concentration-dependently reduced the UV-absorption intensity of P-selectin at 280 nm. THCMA and PSI-697 mixed at both 1:1 (Figure 2E) 
and 1:3 (Figure 2F) concentration-dependently caused hypochromic effects in P-selectin at $280 \mathrm{~nm}$. These results imply that THCMA binds to P-selectin in a similar way to PSI-697.

Protein UV absorbance comes mainly from the aromatic residues tryptophan and tyrosine. ${ }^{39}$ The binding site of PSI-697 and THCMA on P-selectin is surrounded by multiple tyrosine residues: Tyr5, Tyr10, Tyr18, Tyr44, Tyr45, Tyr48, Tyr49, and Tyr94 (Figure 2G). The hypochromic effect of P-selectin on UV absorbance could have been the influence of the binding of PSI-697 or THCMA.

\section{Competitive Binding of THCMA with P-Selectin Against PSGLI on HL60}

The competitive binding ability of THCMA with P-selectin against the natural ligand - PSGL1 expressed on HL60 cells — was tested with ELISA. Representative images of adhered HL60 cells in plates observed under microscopy are shown in Figure 2J-M. Based on spherical cells with smooth edges, the number of adhered HL60 cells in (Figure 2J-M) was 165, 63, 54, and 43, respectively. Figure $2 \mathrm{H}$ shows that HL60 cell numbers adhered to the fixed P-selectin on ELISA plates were significantly reduced in the presence of THCMA or PSI-697. The inhibition rates of THCMA and PSI-697 at $25 \mu \mathrm{M}$ were $67.04 \%$ and $59.69 \%$. The inhibition rate of THCMA at $100 \mu \mathrm{M}$ was significantly increased to $73.41 \%$. The inhibition rate of PSI-697 at $100 \mu \mathrm{M}$ was not recorded, because of its limited solubility. Analysis of these results shows that the inhibitory effect of THCMA on P-selectin was comparable to PSI-697 at $25 \mu \mathrm{M}$, while the inhibitory effect of THCMA on P-selectin was significantly increased at $100 \mu \mathrm{M}$.

\section{THCMA Molecules Assemble as}

\section{Nanorings}

Self-assembly of amphiphiles into nanostructures is driven by various physical interactions, such as hydrophobic effects, intermolecular $\pi-\pi$ interactions, electrostatic interactions, van der Waals interactions, and hydrogen bonds. ${ }^{40,41}$ We analyzed the probable self-assembly process of the amphiphilic organic molecule THCMA.

\section{THCMA Molecules Aggregate as Tetramers in Water} FT-ICR MS spectra are useful in exploring the intermolecular association of small molecules. To explore selfassembly, a solution of THCMA in methanol (1 nM) was tested with FT-ICR MS. The relationship between polymers was explored using a qCID spectrum. Figure 3A shows THCMA molecules exhibited as monomers (318.14566), dimers (635.28299 minus H), trimers (952.42258 minus $\mathrm{H}$ ), and tetramers (1269.56151 minus $\mathrm{H})$. The qCID spectrum of the tetramers $(1,269.56151$ minus $H)$ showed the trimer, dimer, and monomer peaks. These results show that THCMA monomer can aggregate into dimers, trimers, and tetramers in water.

To characterize the molecular assembly pattern of THCMA, the NOESY 2D ${ }^{1} \mathrm{H}$ NMR spectrum was analyzed, and three interesting cross-peaks are marked with red circles in Figure 3B. These cross-peaks reflect the intermolecular interactions of $3-\mathrm{H}$ and $6-\mathrm{H}, 4-\mathrm{H}$ and $6-\mathrm{H}$, and $10-\mathrm{H}$ and $6-\mathrm{H}$, and mean that interaction distances between these hydrogens were $<5 \AA$.

Based on the interaction information, four energyminimized monomers of THCMA were constructed into a tetramer fulfilling these interaction requirements. The THCMA tetramer presented a ring-shaped conformation of about $2.1 \mathrm{~nm}$ in diameter. The top view and side view of the tetramer are shown in Figure 3C.

\section{THCMA Molecules Assemble as Nanorings}

To visualize the nanofeatures of THCMA, TEM and SEM images were captured on $0.1 \mu \mathrm{M}$ of THCMA solution water solution at $\mathrm{pH} 7$ and its lyophilized powder. TEM showed that THCMA formed tiny nanoparticles of approximately 2$3 \mathrm{~nm}$ in diameter, which in turn assembled into pearl necklace-like nanorings in of around $100 \mathrm{~nm}$ diameters (Figure 4A). Analysis of 400 nanoparticles in the TEM image showed nanoparticle-size distribution of 94.83 $\pm 22.76 \mathrm{~nm}$ (Figure 4B). The diameter of the tiny nanoparticles in TEM image $(2-3 \mathrm{~nm})$ was approximately the diameter of the bilayer formed by two THCMA tetramers. SEM showed that THCMA forms hollow nanorings in diameters of around $100 \mathrm{~nm}$ (Figure 4C). Analysis of 400 nanoparticles in the SEM image shows a nanoparticle size distribution of in $99.53 \pm 23.69 \mathrm{~nm}$ (Figure 4D). A probable self-assembly process is proposed in Figure 4E. The amphiphilic organic molecule THCMA self-assembled as a bilayer nanoring with the lipophilic parts exposed to the aqueous environment (Figure 4E). The formation of the THCMA nanostructure is good for drug-delivery efficiency.

\section{Nanoproperties of Aqueous THCMA}

The nanofeatures of THCMA water solution was characterized with the Tyndall effect excited by $650 \mathrm{~nm}$ laser, 
A

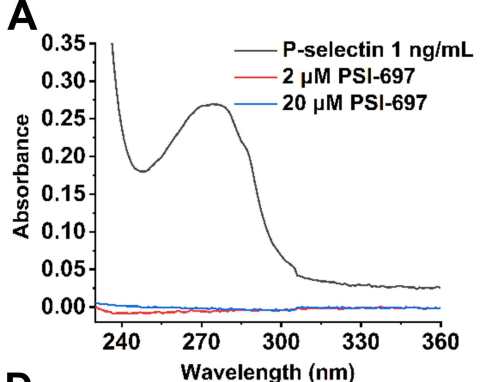

D

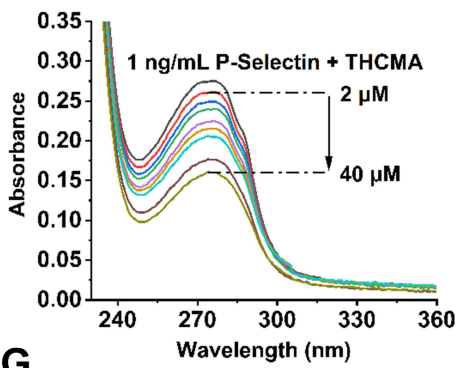

G
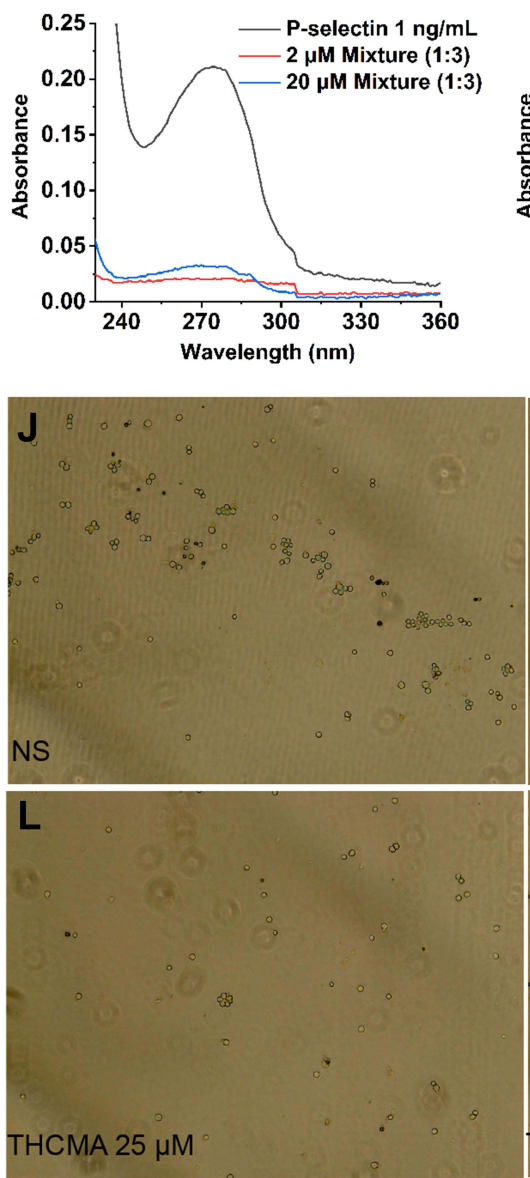

B

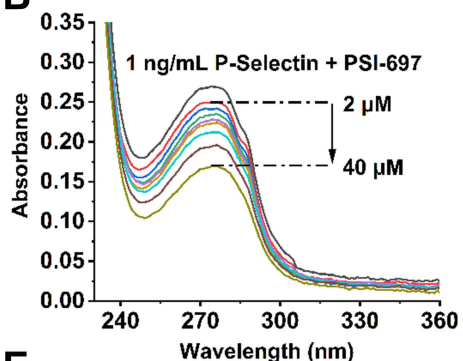

E
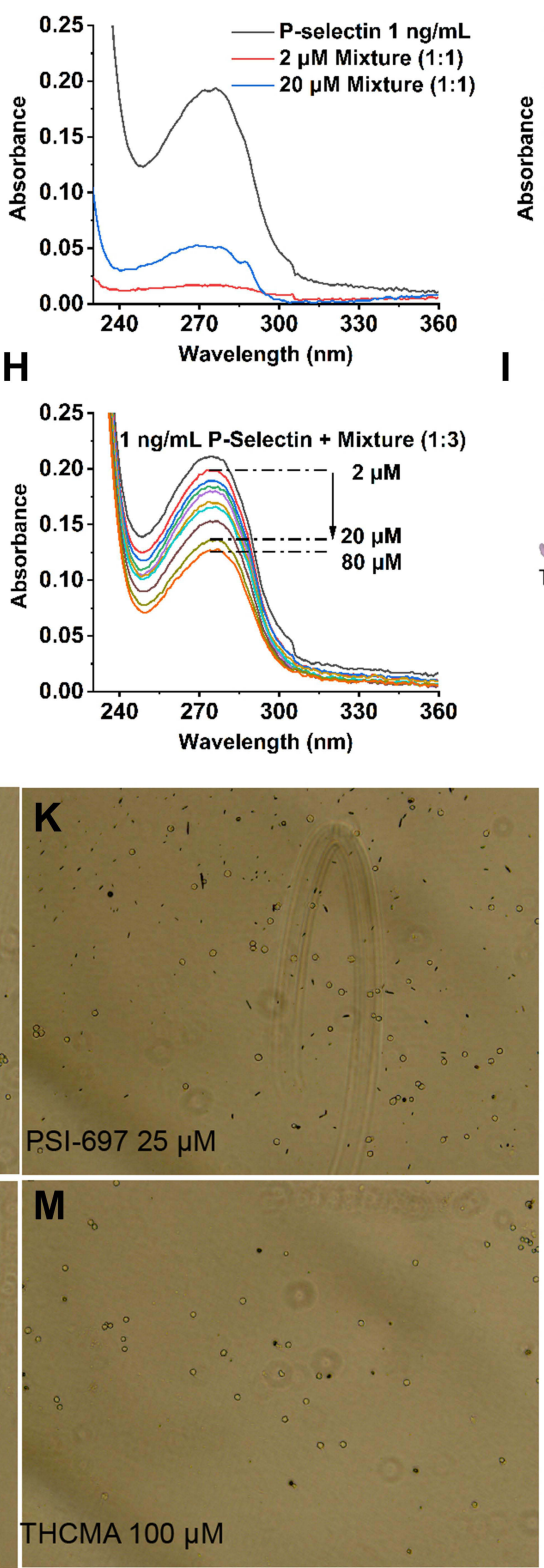

C

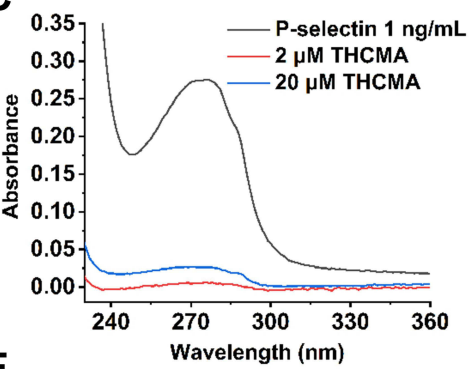

F

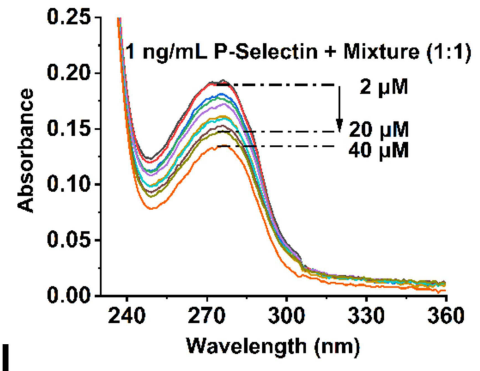

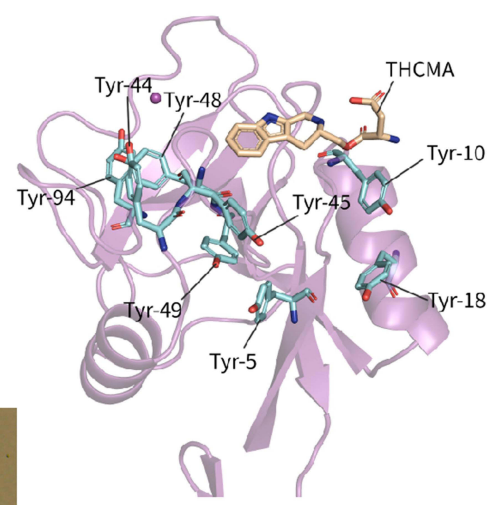

$\mathbf{N}$

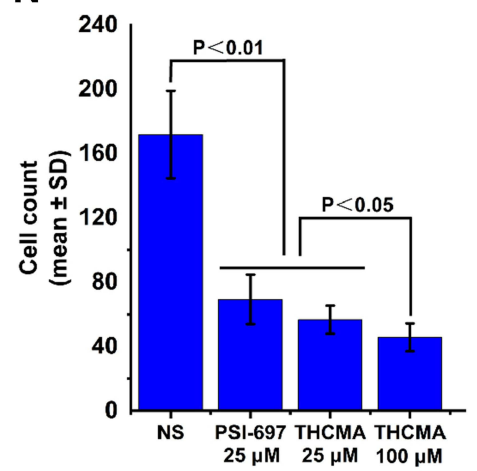

Figure 2 UV spectra of P-selectin influenced by the binding of THCMA and competitive binding of THCMA to P-selectin against PSGLI expressed on HL60 cells. (A) UV spectra of sPselectin and PSI-697 (2 $\mu \mathrm{M}, 20 \mu \mathrm{M})$. (B) UV spectra of increasing amount of PSI-697 with sP-selectin. (C) UV spectra of sP-selectin and THCMA (2 $\mu$ M, $20 \mu \mathrm{M})$. (D) UV spectra of increasing amount of THCMA with sP-selectin. (E) UV spectra of sP-selectin and I:I mixture solution (THCMA:PSI-697 I:I, total $2 \mu M, 20 \mu M)$. (F) UV spectra of increasing amount of I:I mixture solution with sP-selectin. (G) UV spectra of sP-selectin and I:3 mixture solution (THCMA:PSI-697 I:3, total $2 \mu M, 20 \mu M)$. (H) UV spectra of increasing amount of I:3 mixture solution with sP-selectin. (I) Multiple P-selectin tyrosine residues located adjacent to the binding site of THCMA, perhaps attributable to the UV spectra changes of P-selectin. (J) Microscopy of HL60 cells adhered to fixed P-selectin treated with NS. (K) Microscopy of HL60 cells adhered to fixed P-selectin treated with $25 \mu M$ PSI-697. (L) Microscopy of HL60 cells adhered to fixed P-selectin treated with $25 \mu$ MTHCMA. (M) Microscopye of HL60 cells adhered to fixed P-selectin treated with $100 \mu M$ THCMA. (N) HL60 cell numbers adhered to the fixed P-selectin on ELISA plates in the presence and absence of THCMA and PSI-697. 
A

Intens

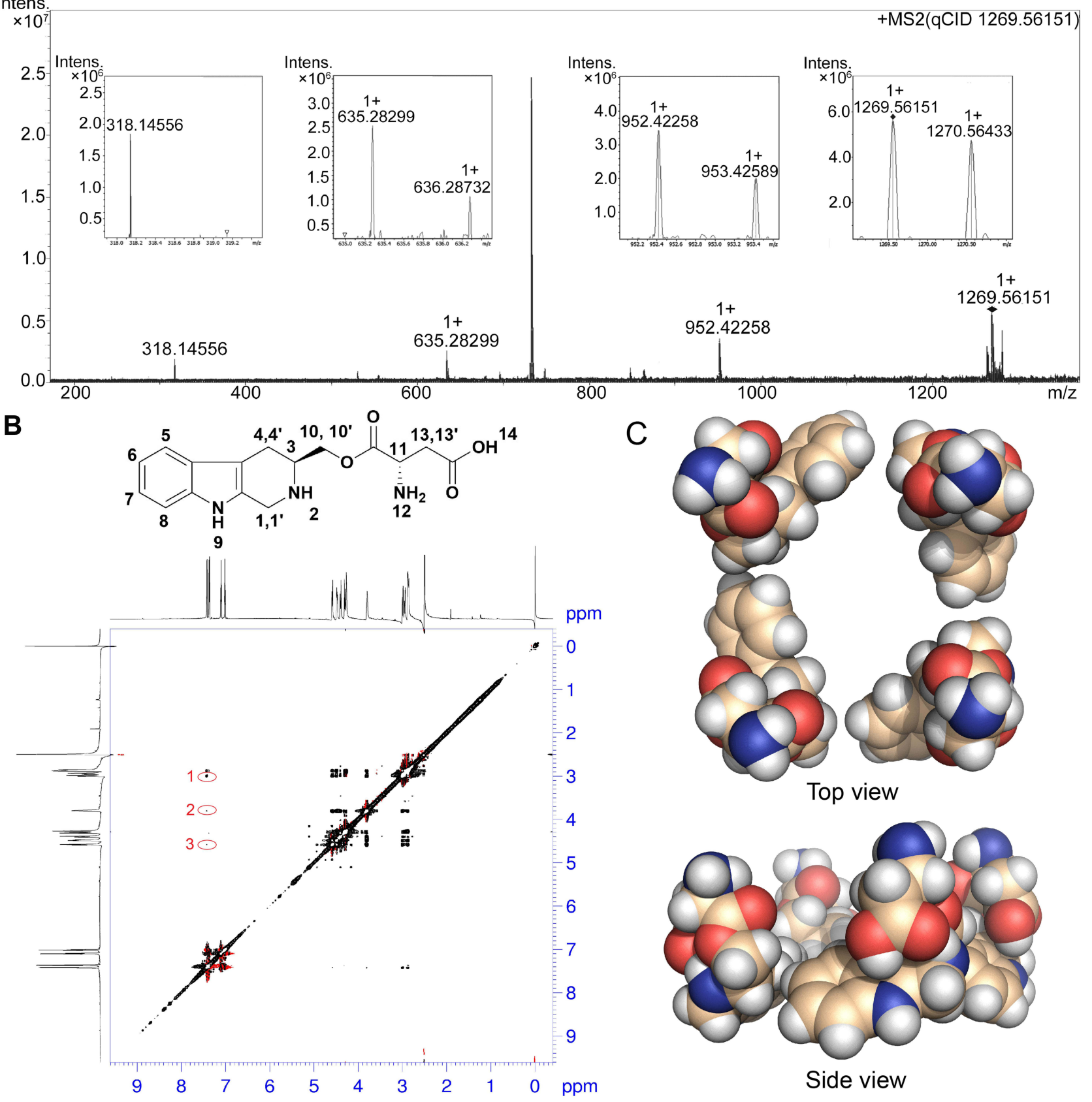

Figure 3 FT-ICR-MS, qCID, NOESY spectra, and THCMA tetramer: (A) FT-ICR-MS spectrum presents peaks of THCMA monomer (3I8.I4566), dimer (635.28299 minus $H$ ), trimer ( 952.42258 minus $H)$, and tetramer (I,269.56I5I minus H). qCID spectrum of the THCMA tetramer (I,269.56I5I minus $H)$ splits into peaks of trimer, dimer, and monomer. (B) NOESY 2D 'H NMR spectrum presents three cross-peaks in red circles reflecting the intermolecular interactions between 3-H and 6-H, 4- $\mathrm{H}$ and 6-H, and $\mathrm{I0}-\mathrm{H}$ and 6-H. (C) Top view and side view of the constructed THCMA tetramer (CPK model) fulfilling NOESY interaction requirements.

Abbreviation: NOESY, nuclear Overhauser-effect spectroscopy.

particle size over 7 days, and $\zeta$-potentials. It can be seen in Figure $5 \mathrm{~A}$ and $\mathrm{F}$ that ultrapure water of various $\mathrm{pH}$ exposed to $650 \mathrm{~nm}$ laser did not exhibit a Tyndall effect. Figure 5B-E, and 5G-J indicate that the Faraday-Tyndall effect occurred at various concentrations of THCMA solutions $(10,1,0.1$, and $0.01 \mu \mathrm{M})$ at both $\mathrm{pH} 7$ and 2 . These results imply that THCMA exhibits as nanoparticles at $\mathrm{pH} 7$ and $\mathrm{pH} 2$ (gastric fluid).

The $\zeta$-potentials of 10, 1, 0.1 and $0.01 \mu \mathrm{M}$ THCMA solutions at $\mathrm{pH} 7$ were $-11.9 \mathrm{mV},-19.1 \mathrm{mV},-17.6 \mathrm{mV}$, and 

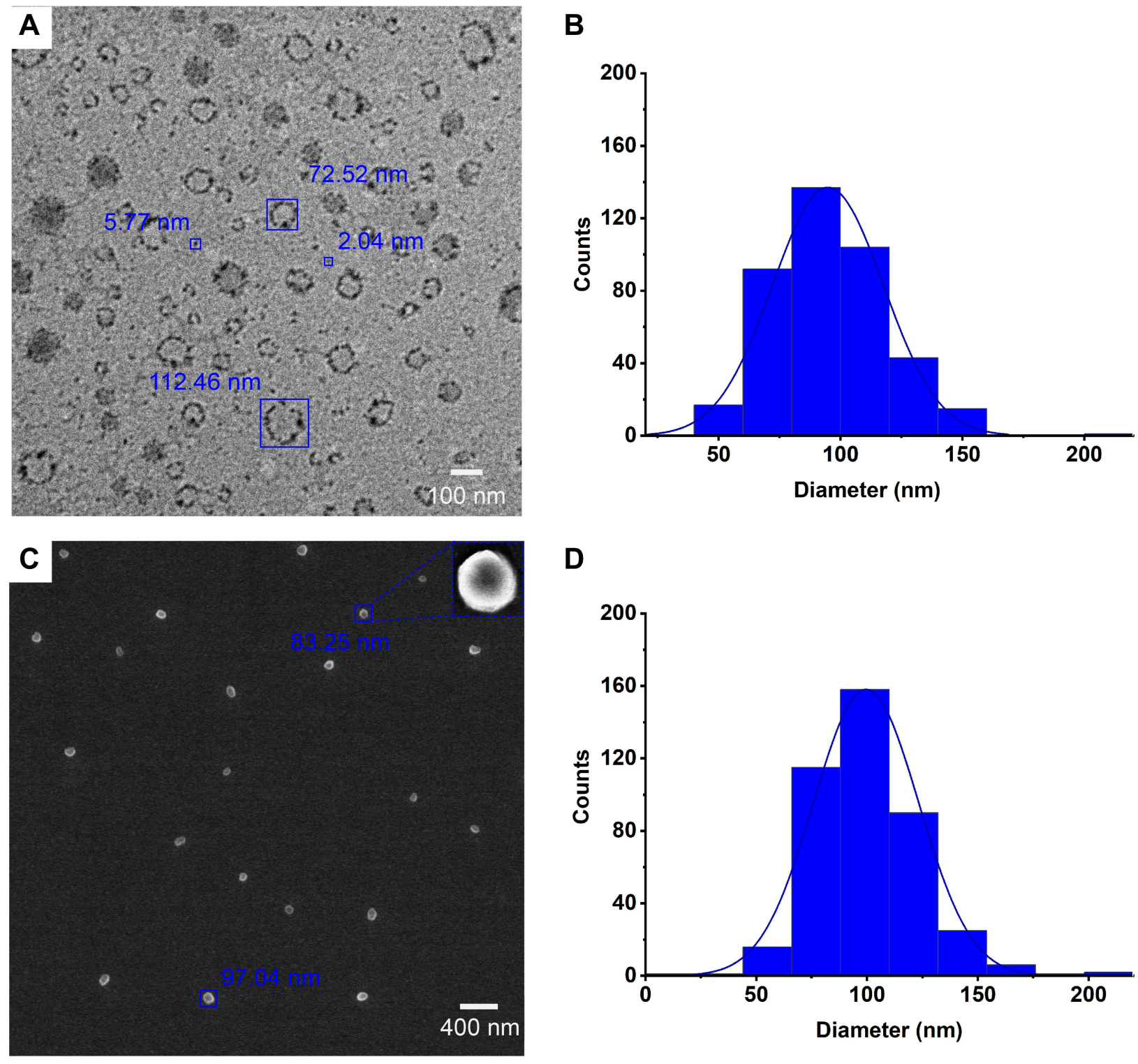

D

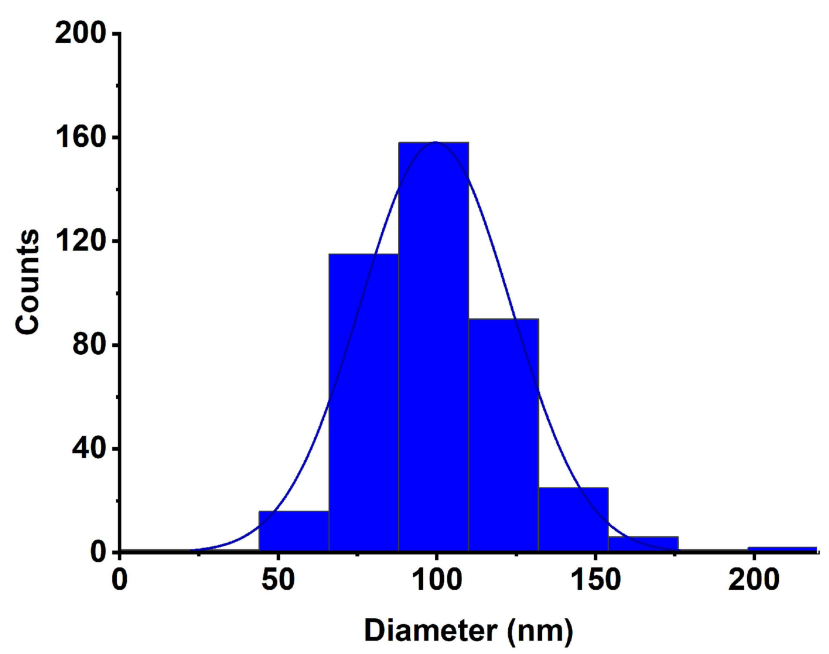

$\mathbf{E}$
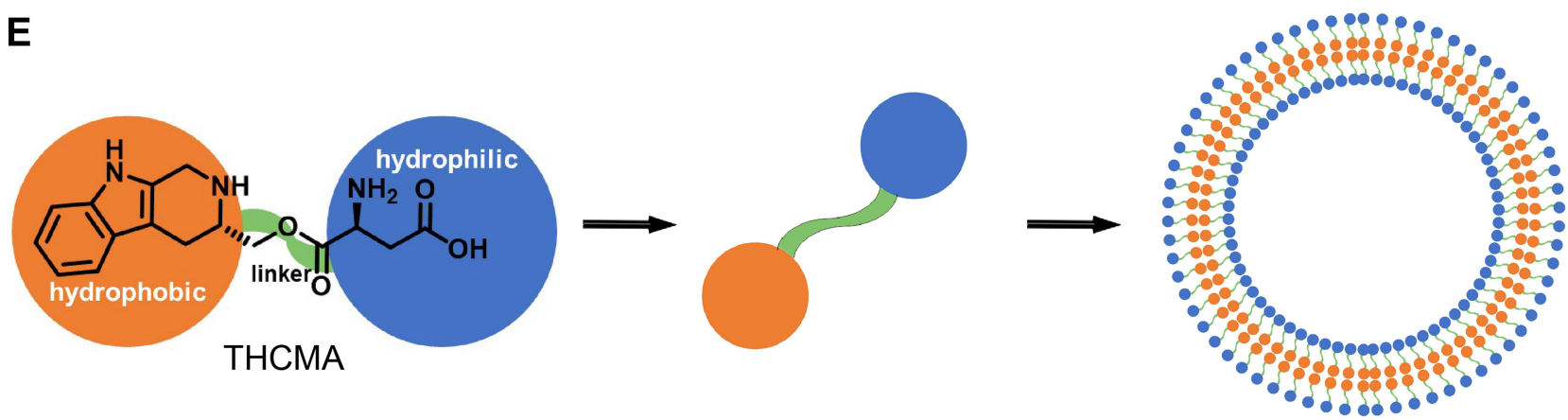

Figure 4 TEM and SEM images, nanoparticle-size distribution, and proposed self-assembly pattern of THCMA nanostructure. (A) TEM of 0.I $\mu M$ THCMA water solution at $\mathrm{pH}$ 7. (B) Statistical nanoparticle size distribution of THCMA on TEM $(n=400)$. (C) SEM of lyophilized powder of THCMA. (D) Nanoparticle size distribution of THCMA on SEM $(n=400)$. (E) Proposed self-assembly pattern of THCMA nanostructure.

Abbreviations: TEM, transmission electron microscopy; SEM, scanning electron microscopy. 
$-23.7 \mathrm{mV}$, respectively (Figure $5 \mathrm{~K}-\mathrm{N}$ ). The $\zeta$-potential of pH 7 THCMA water solution at $10 \mu \mathrm{M}$ was lower than those at $1 \mu \mathrm{M}, 0.1 \mu \mathrm{M}$, and $0.01 \mu \mathrm{M}$. A possible reason is that higher concentrations of THCMA water solution had more tendency to aggregate and coagulate. Nanoparticle sizes in pH 7 THCMA solutions (10, 1, 0.1,
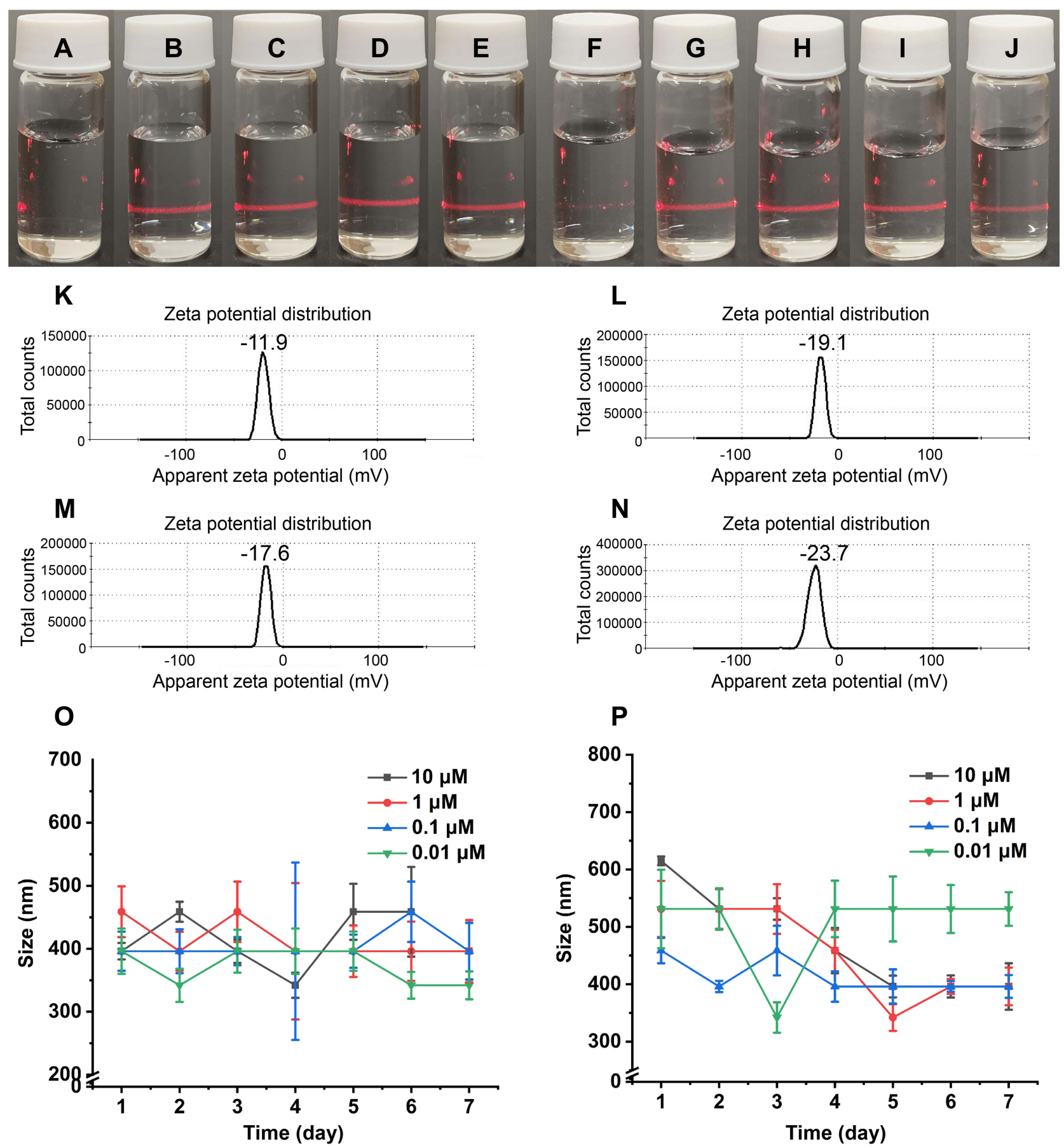

Figure 5 Tyndall effect excited by $650 \mathrm{~nm}$ laser $(\mathbf{A}-\mathbf{J})$, $\zeta$-potential $(\mathbf{K}-\mathbf{N})$ and particle size of THCMA in water over time (O and, P): (A) ultrapure water; (B) $10 \mu M$ of THCMA water solution at $\mathrm{pH} 7.0$; (C) I $\mu \mathrm{M}$ of THCMA water solution at $\mathrm{pH} 7$; (D) $0.1 \mu \mathrm{M}$ THCMA water solution at $\mathrm{pH} 7$; (E) $0.0 \mathrm{I} \mu \mathrm{M}$ THCMA water solution at $\mathrm{pH} 7$; (F) $\mathrm{HCl}$ solution at $\mathrm{pH} 2$; (G) $10 \mu \mathrm{M}$ THCMA water solution at $\mathrm{pH} 2$; (H) I $\mu$ M THCMA water solution at $\mathrm{pH} 2$; (I) $0.1 \mu \mathrm{M}$ THCMA water solution at $\mathrm{pH} 2$; (J) $0.0 \mathrm{I} \mu \mathrm{M}$ THCMA water solution at $\mathrm{pH} 2$; $(\mathbf{K}) \zeta$-potential of THCMA water solution ( $\mathrm{pH} 7,10 \mu \mathrm{M})$; (L) $\zeta$-potential of THCMA water solution (pH 7, I $\mu$ M); (M) $\zeta$-potential of THCMA water solution ( $\mathrm{pH} 7,0.1 \mu \mathrm{M})$; (N) $\zeta$-potential of THCMA water solution ( $\mathrm{pH} 7,0.0 \mathrm{I} \mu \mathrm{M})$; (O) Particle size of THCMA water solutions over 7 days at pH 7 (I0, I, 0.1 , and $0.01 \mu \mathrm{M})$; $(\mathbf{P})$ particle size of THCMA solutions over 7 days at $\mathrm{pH} 2(10,1,0.1$, and $0.01 \mu \mathrm{M})$. 
and $0.01 \mu \mathrm{M})$ fluctuated $(350-450 \mathrm{~nm}$ over 7 days, Figure 5O), while $\mathrm{pH} 2$ THCMA solutions (10, 1, 0.1 and $0.01 \mu \mathrm{M})$ also fluctuated $(350-650 \mathrm{~nm}$ over 7 days, Figure 5P). These results indicate that THCMA solutions maintained more stable nanoparticles in $\mathrm{pH} 7$ than $\mathrm{pH} 2$.

\section{Anti-Arterial Thrombosis Activity of THCMA In Vivo}

THCMA was given orally to rats in the arteriovenous shuntsilk-thread model to evaluate its anti-arterial thrombosis activity. It can be seen in Figure 6A that $5 \mu \mathrm{mol} / \mathrm{kg}$ P-selectin inhibitor PSI-697 effectively inhibited the formation of arterial thrombus in rats. However, THCMA exhibited better oral efficacy than PSI-697 at 100-fold lower dosage. The oral efficacy of THCMA dosedependently increased. The anti-arterial thrombosis activity of $0.05 \mu \mathrm{mol} / \mathrm{kg}$ THCMA shows no significant difference with $167 \mu \mathrm{mol} / \mathrm{kg}$ aspirin (positive control). These results suggested $>100$-fold improved oral efficacy of THCMA over PSI-697 in inhibiting the formation of arterial thrombus.

\section{Anti-Venous Thrombosis Activity of THCMA In Vivo}

THCMA was given orally to rats in the IVC-ligation model to evaluate its anti-venous thrombosis activity. It can be seen in Figure 6B that $5 \mu \mathrm{mol} / \mathrm{kg}$ PSI-697 and $0.05 \mu \mathrm{mol} / \mathrm{kg}$ THCMA decreased the venous thrombus weight of rats to a similar level. Oral treatment of $0.5 \mu \mathrm{mol} / \mathrm{kg}$ THCMA showed no significant difference to oral treatment of 4.87 $\mu \mathrm{mol} / \mathrm{kg}$ warfarin (positive control) on venous thrombus weight. Moreover, the oral anti-venous thrombosis activity of THCMA was significantly improved with increased dosage. These results suggest that the oral efficacy of THCMA is tenfold that of warfarin and 100-fold that of PSI-697 in inhibiting the formation of venous thrombus.

\section{Bleeding-Risk Evaluation of THCMA}

The bleeding risk of THCMA was evaluated by the bleeding time of rat tails. Figure $6 \mathrm{C}$ shows that oral treatment of $4.87 \mu \mathrm{mol} / \mathrm{kg}$ warfarin in venous thrombosis assays caused prolonged tail bleeding compared to oral treatment of $3 \mathrm{~mL} / \mathrm{kg} \mathrm{CMCNa}$ in the negative-control group rats, which indicates the bleeding risk of warfarin. On the contrary, oral treatment of $5 \mu \mathrm{mol} / \mathrm{kg}$ THCMA or PSI697 did not increase bleeding time, which excludes their bleeding risk.

\section{Influence on Coagulation Function of THCMA}

To test the influence of THCMA on coagulation function sera of rats from venousthrombosis assays were tested for PT, TT, APTT, and Fib. Figure 6D shows that these values after oral treatment of $5 \mu \mathrm{mol} / \mathrm{kg}$ THCMA or PSI-697 were not significantly different from the negative-control group. However, the rats exhibited unusual APTT values after oral treatment of $5 \mu \mathrm{mol} / \mathrm{kg}$ warfarin. These results suggest that coagulation function was not influenced by oral treatment of $5 \mu \mathrm{mol} / \mathrm{kg}$ THCMA and PSI-697.

\section{Anti-Inflammation Activity of THCMA In Vivo}

THCMA was given orally to mice in a xylene-induced earedema model to evaluate its anti-inflammation activity. In the assay, CMCNa was used as blank control and aspirin as positive control. To examine the relationship between anti-inflammation activity and P-selectin inhibition, the anti-inflammation activity of PSI-697 was tested. Figure 7A shows that the inhibition level of THCMA on ear-edema of mice was significantly enhanced with increased dosage. Oral treatment of $0.5 \mu \mathrm{mol} / \mathrm{kg}$ THCMA, $5 \mu \mathrm{mol} / \mathrm{kg}$ PSI-697, and $1,110 \mu \mathrm{mol} / \mathrm{kg}$ aspirin exhibit similar inhibition levels. Oral treatment of $5 \mu \mathrm{mol} /$ kg THCMA presented significantly higher antiinflammation activity than $5 \mu \mathrm{mol} / \mathrm{kg}$ PSI-697. THCMA showed tenfold-enhanced anti-inflammation activity compared to PSI-697, and anti-inflammation activity was related to the P-selectin inhibition of THCMA.

\section{Anti-Tumor Growth Activity of THCMA In Vivo}

THCMA was given orally to S180-bearing mice to evaluate its in vivo antitumor activity. Figure 7B shows that tumor weight after oral treatment of $5 \mu \mathrm{mol} / \mathrm{kg} /$ day THCMA was significantly less than with $5 \mu \mathrm{mol} / \mathrm{kg} / \mathrm{day}$ PSI-697. There was no significant difference in tumor weight between $5 \mu \mathrm{mol} / \mathrm{kg} /$ day THCMA and $2 \mu \mathrm{mol} / \mathrm{kg} /$ day Dox. These results imply that oral treatment with THCMA and PSI-697 exhibit potential in slowing tumor growth, and THCMA exhibits similar antitumor activity to Dox and better antitumor activity than PSI-697.

\section{Systemic Toxicity of THCMA}

To evaluate the systemic toxicity of THCMA, body weight and organ:body-weight ratio of S180-bearing 


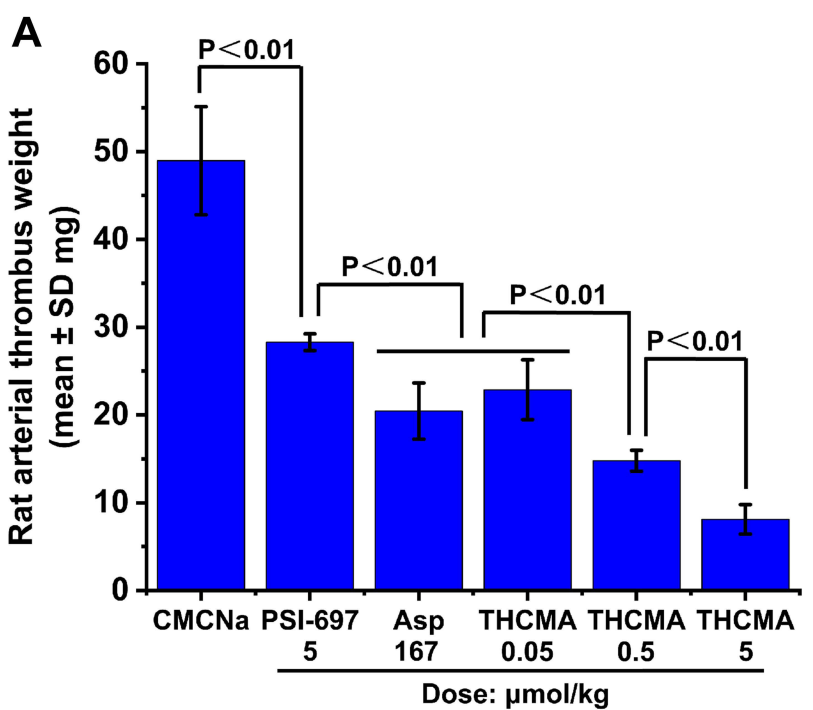

C

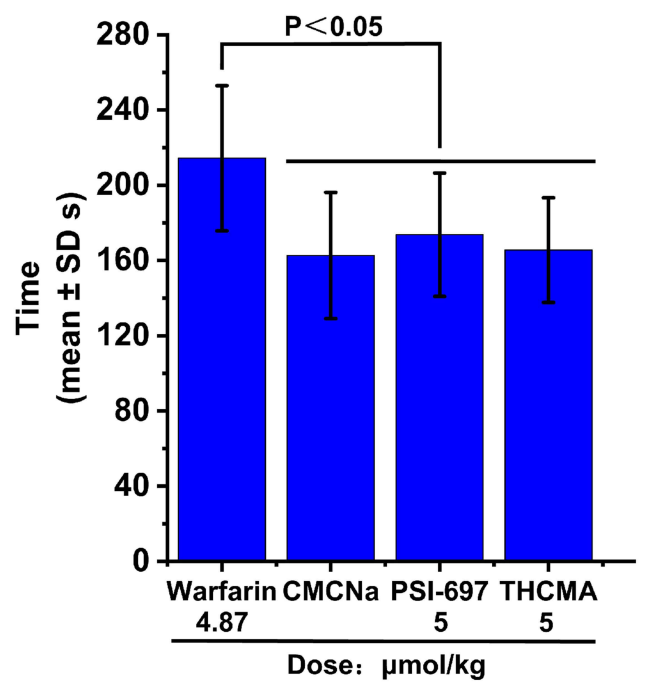

B

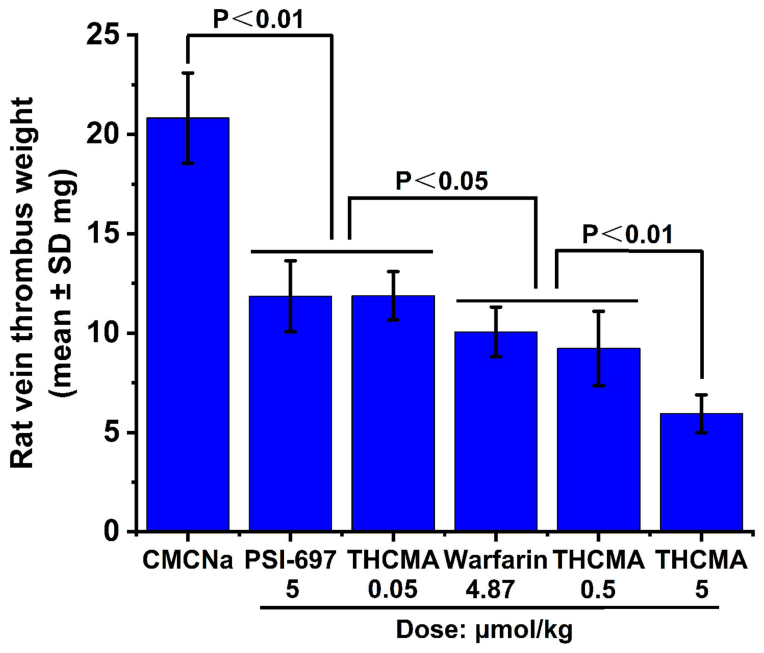

D

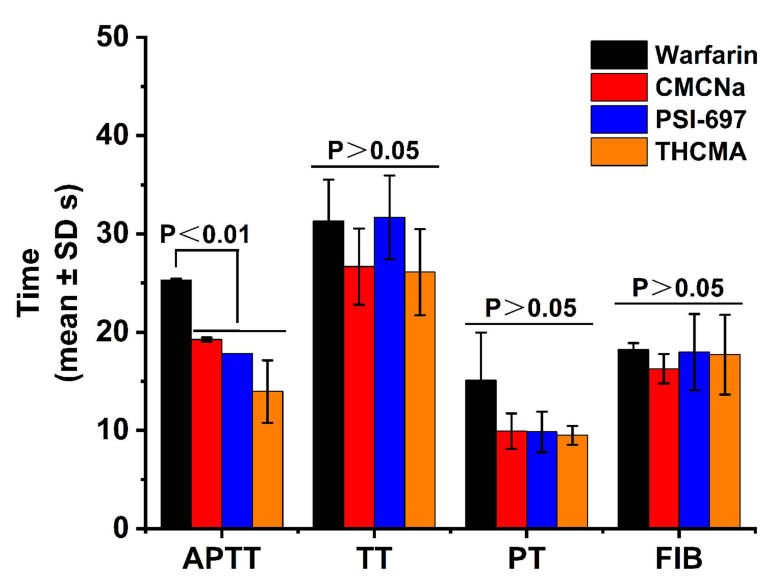

Figure 6 Antithrombosis activity and bleeding-risk, and coagulation-risk evaluations of THCMA. (A) Anti-arterial thrombosis activity of THCMA ( $\mathrm{n}=10$ ); (B) antivenous thrombosis activity of THCMA $(n=10)$; $(\mathbf{C})$ bleeding risk of THCMA $(n=10)$; (D) coagulation indices (PT, TT, APTT, Fib) of THCMA ( $n=6)$.

Abbreviations: Asp, aspirin; PT, prothrombin time; TT, thrombin time; APTT, activated partial thromboplastin time; Fib, fibrinogen.

mice were calculated to evaluate body and organ atrophy. Figure $7 \mathrm{C}$ shows that the body weight of mice treated with THCMA was similar to that of $\mathrm{CMCNa}$, while the body weight of mice treated with Dox was significantly less than that of CMCNa. Figure 7D shows that the liver:body-weight ratio and spleen:bodyweight ratio of mice treated with THCMA were similar to that of $\mathrm{CMCNa}$, but significantly higher than that of Dox. These results mean that THCMA does not exhibit systemic toxicity, while Dox does.

\section{Downregulation of sP-Selectin and TNF $\alpha$ Expression by THCMA In Vivo}

sP-selectin is the extra membrane domain of P-selectin shed from the plasma membrane. The expression level of sPselectin is considered a biomarker of inflammation, platelet activation, and vascular and thrombotic diseases. ${ }^{42-44}$ To reveal the correlation of THCMA's P-selectin inhibition activity with its antithrombosis, anti-inflammation, and antitumor activity, in vivo expression levels of sP-selectin and $\mathrm{TNF} \alpha$ were examined. Figure 8A-D show that expression 
A

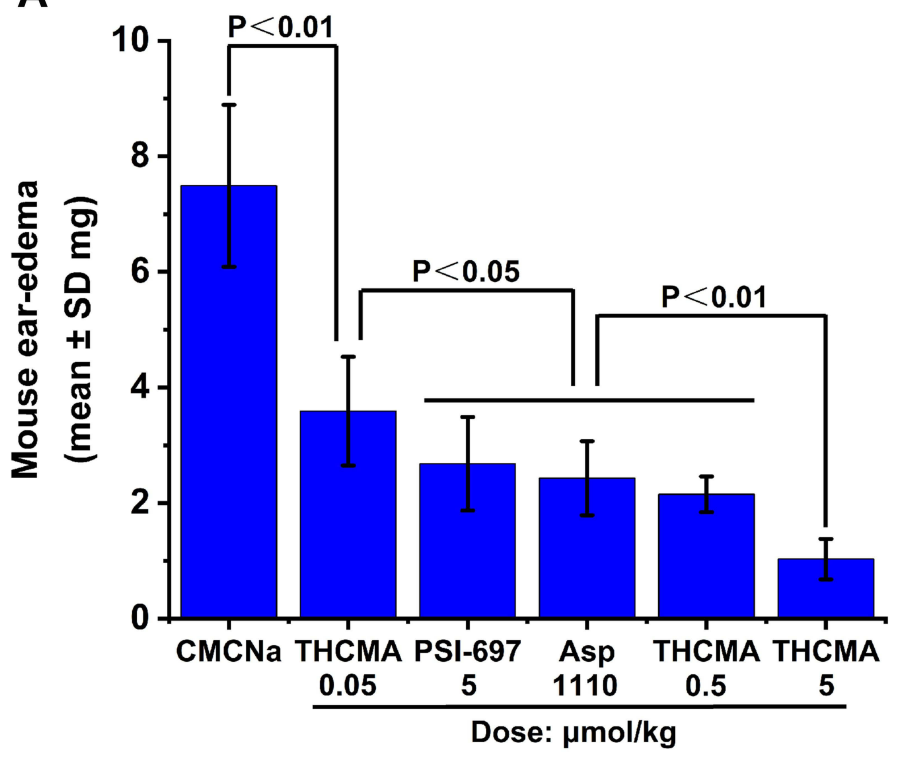

B

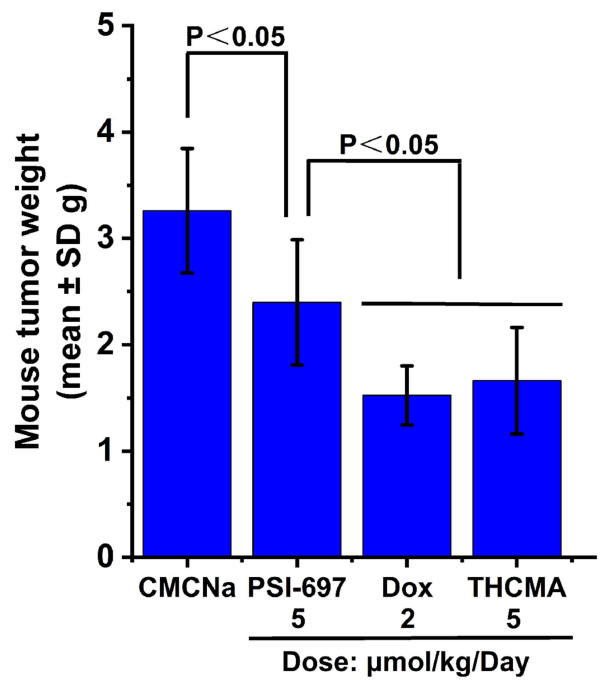

C

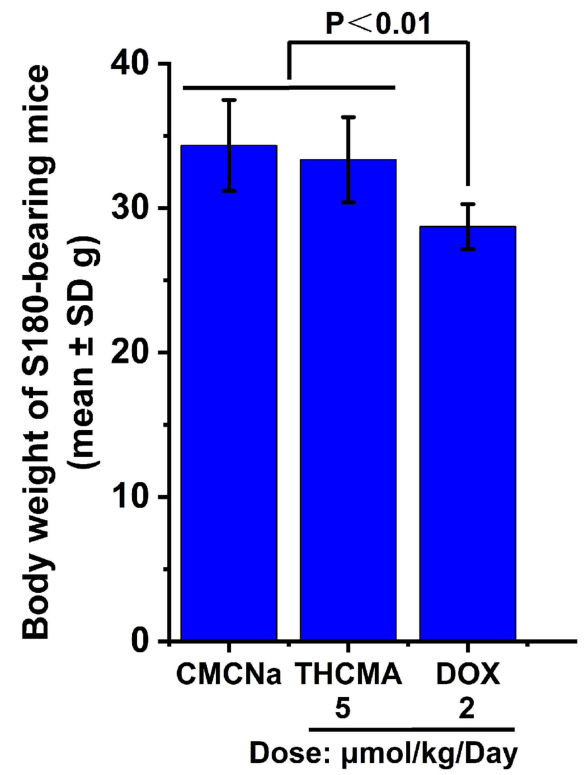

D

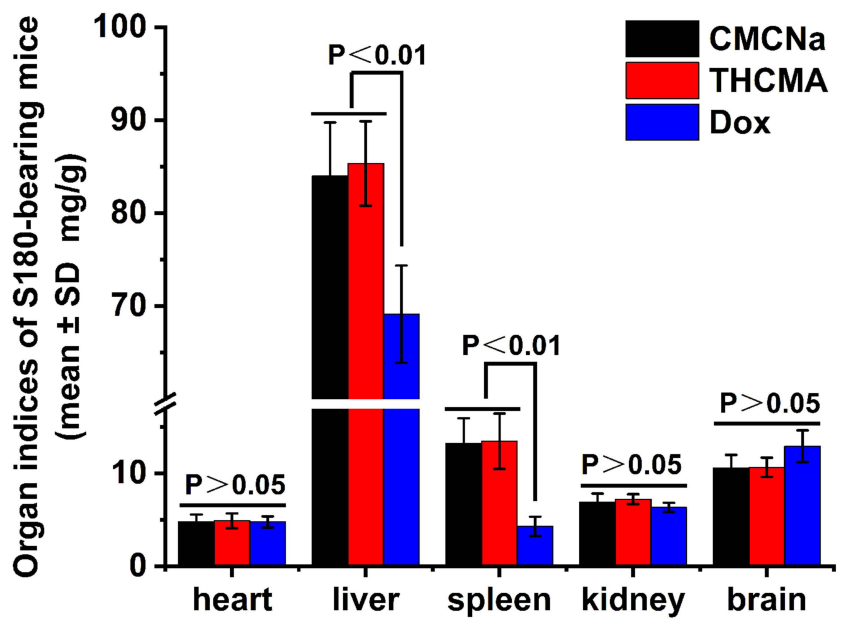

Figure 7 Anti-inflammation and antitumor activity and systemic toxicity of THCMA. (A) Anti-inflammation activity of THCMA ( $\mathrm{n}=10)$; (B) antitumor activity of THCMA $(n=6)$; (C) effect of THCMA on body weight in SI80-bearing mice $(n=8)$; (D) effect of THCMA on organ:body-weight ratios of SI80-bearing mice $(n=8)$.

Abbreviations: Asp, aspirin; Dox, doxorubicin.

levels of sP-selectin in arterial thrombosis rats, venous thrombosis rats, S180 mice, and ear-edema mice had similar patterns. sP-selectin expression in animals treated with THCMA or PSI-697 were significantly lower than in animals treated with negative or positive control. Expression of sP-selectin was downregulated to a similar extent after treatment with THCMA or PSI-697 in venous thrombosis rats, S180 mice, and ear-edema mice. These results indicated that in vivo antithrombosis, antitumor, and anti-inflammation activity of THCMA and PSI-697 were directly related to their $\mathrm{P}$-selectin inhibition activity. It is worth noting that expression of sP-selectin in arterial thrombosis rats in the THCMA group was significantly lower than the PSI-697 group, which implies that the anti-arterial thrombosis activity was more sensitive to P-selectin inhibition. THCMA exhibited stronger downregulation of $\mathrm{sP}$ - 


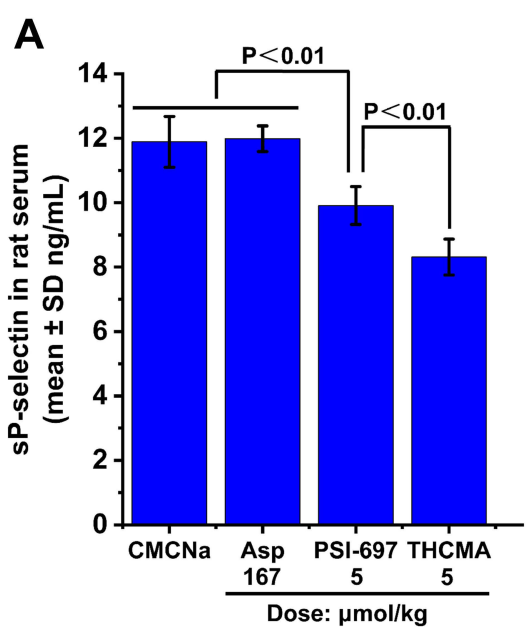

D

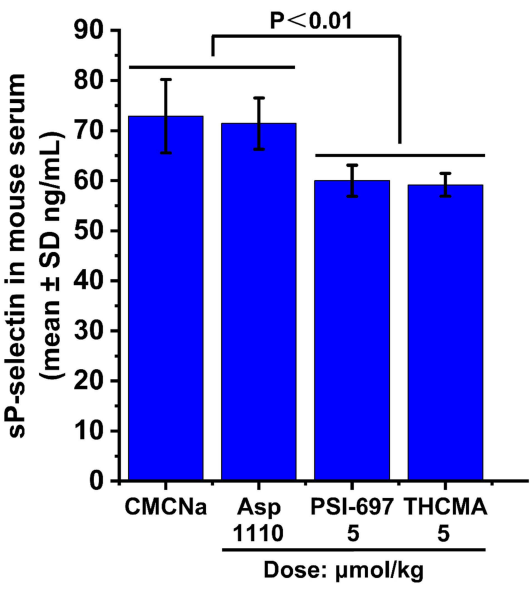

B

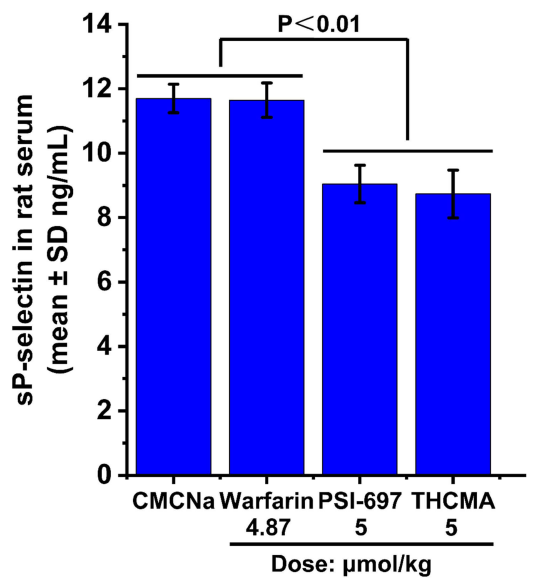

C

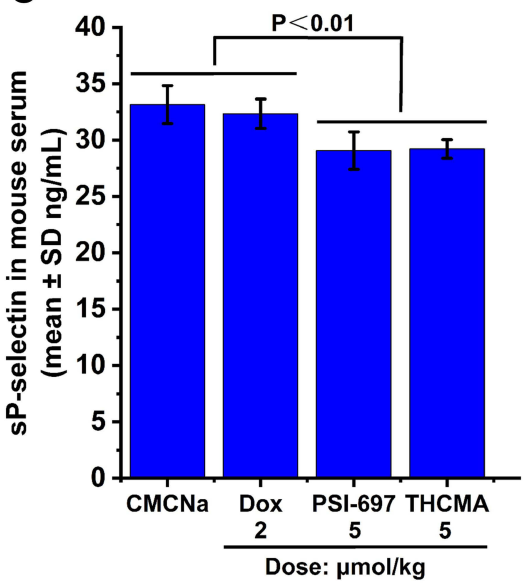

E

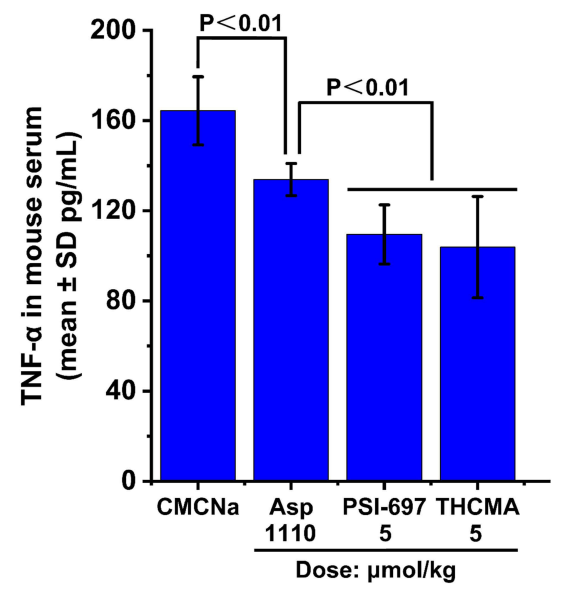

Figure 8 Expression levels of sP-selectin and TNF $\alpha$ in vivo $(n=8)$. (A) sP-selectin expression in arterial thrombosis rats; (B) sP-selectin expression in venous thrombosis rats; (C) sP-selectin expression in SI80 mice; (D) sP-selectin expression in ear-edema mice; (E) TNF $\alpha$ expression in ear-edema mice.

selectin than PSI-697. This means that THCMA has more potential in inhibiting arterial thrombosis, which is in accordance to the in vivo data.

$\mathrm{TNF} \alpha$ levels were significantly decreased in ear-edema mice treated with aspirin and P-selectin inhibitors THCMA and PSI-697, and significantly lower in mice treated with 5 $\mu \mathrm{mol} / \mathrm{kg}$ P-selectin inhibitors than mice treated with 1110 $\mu \mathrm{mol} / \mathrm{kg}$ aspirin (Figure $8 \mathrm{E}$ ). These results imply that inhibition of P-selectin may also indirectly inhibit inflammation by downregulating the expression of TNF $\alpha$ in mice, which is closely related to inflammation.

\section{In Vitro Antiplatelet Activity of THCMA}

To further study the mechanism of THCMA inhibiting arterial thrombosis and tumor growth, ${ }^{2}$ the antiplatelet activity of THCMA was evaluated in two ways: AFM of platelets in the presence and absence of THCMA and in vitro plateletaggregation assay. Figure 9A shows resting rat platelets on
AFM. It can be seen that most platelets were scattered and unaggregated. The curve at the top represents height changes across the surface of the single platelet marked by the red square. The curve is smooth, indicating that the platelet surface is smooth. Figure 9B shows rat platelets activated by AA on AFM. It can be seen that most platelets were aggregated and the surface of the activated platelet was still smooth. Figure 9C-E shows AFM of rat platelets activated by $\mathrm{AA}$ in the presence of 10,1 , and $0.1 \mu \mathrm{M}$ THCMA, respectively. Aggregation of rat platelets was dosedependently inhibited in the presence of THCMA. The height curves at the top of Figure 9C-E show differences of 120.92, 110.97, and $91.98 \mathrm{~nm}$, respectively. These results imply the adhesion of THCMA nanoparticles on the surface of platelets.

The anti-platelet aggregation activity of THCMA and PSI-697 were assessed by inhibition rates of platelet aggregation in the presence of THCMA and PSI-697. 

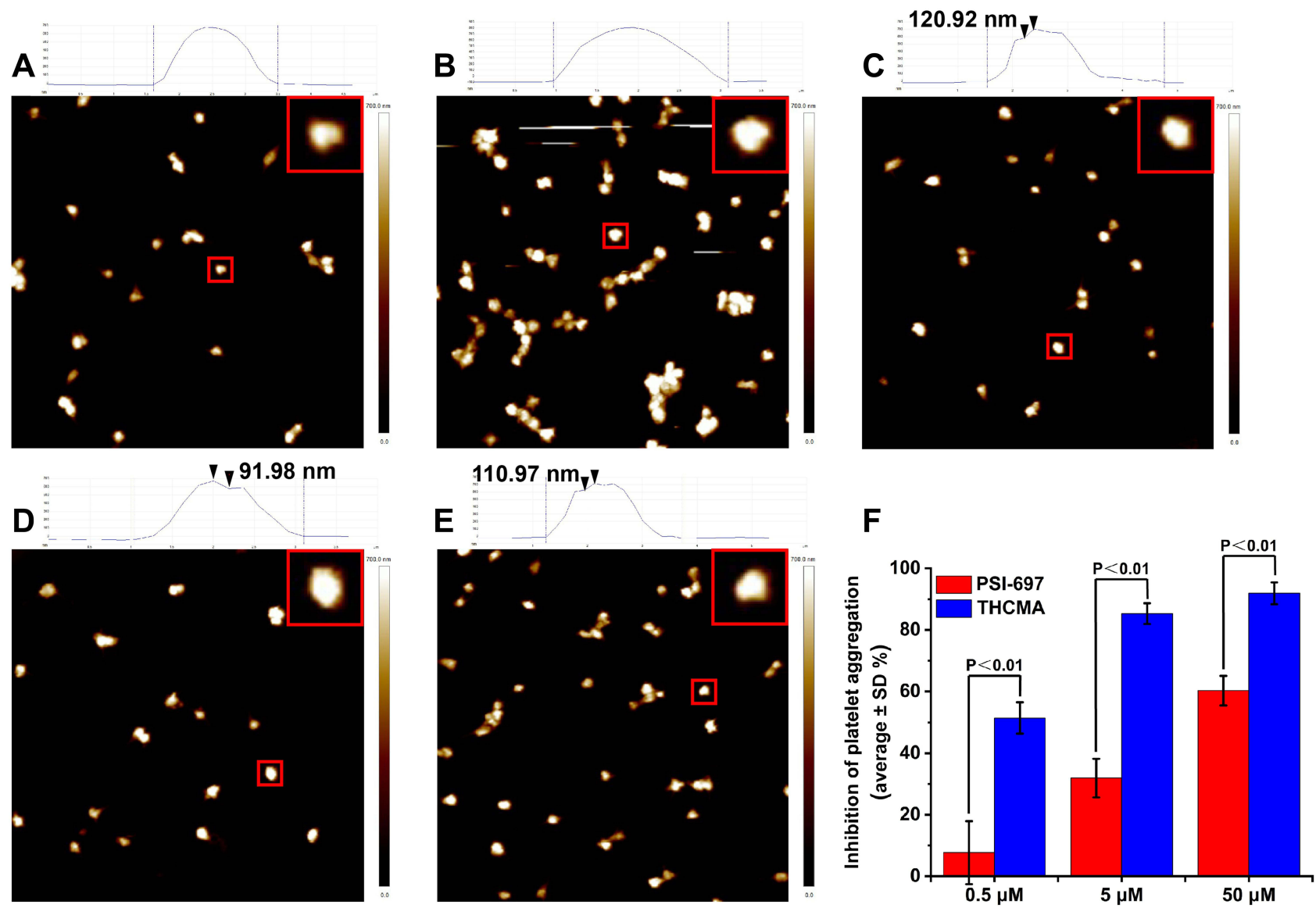

Figure 9 AFM images of platelets at various states with the height of marked platelet shown at top, and anti-platelet aggregation activity of THCMA in vitro. (A) AFM of rat platelets at resting state; (B) AFM of rat platelets activated by AA; (C) AFM of rat platelets activated by AA in the presence of I0 $\mu$ M THCMA; (D) AFM of rat platelets activated by AA in the presence of I $\mu$ M THCMA; (E) AFM of rat platelets activated by AA in the presence of $0.1 \mu M$ THCMA; (F) anti-platelet aggregation activity of THCMA and PSI-697 in vitro $(n=6)$.

Abbreviation: $\mathrm{AA}$, arachidonic acid.

Figure 9F shows that inhibition was $51.43 \%, 85.28 \%$, and $91.05 \%$ in the presence of $0.5,5$, and $50 \mu \mathrm{M}$ of THCMA, respectively, and $7.65 \%, 31.93 \%$, and $60.26 \%$ in the presence of $0.5,5$, and $50 \mu \mathrm{M}$ PSI-697, respectively. These results indicate that THCMA can effectively inhibit platelet aggregation and significantly enhance anti-platelet aggregation activity compared to PSI-697.

\section{Discussion}

Several studies have shown that PSI-697 exhibits oral activity for the treatment of atherosclerosis, restenosis and venous thrombosis in animals, ${ }^{20,21,45-47}$ while its activity and solubility need improvement. In the present work, we designed a new small-molecule THCMA as a P-selectin inhibitor. THCMA contains two pharmacophores of PSI-697 connected by a linker (Figure 1C). Two pharmacophores were designed for oral activity as a P-selectin inhibitor, and connected with a linker to form an amphiphilic molecule for improved solubility as an oral drug and improved drug delivery through self-assembly into nanomedicine. The solubility test showed that the maximum water solubility of THCMA was 1,030-fold that of PSI-697, which is good for the development of an oral drug active in vessels.

\section{THCMA Confirmed as a New}

\section{Small-Molecule P-Selectin Inhibitor}

In silico molecular docking studies suggested that the two pharmacophores of THCMA bound at the Tys48 binding site and interacted with P-selectin in a similar way to PSI697 (Figure 1D). In vitro UV spectra (Figure 2A-D) also showed that THCMA and PSI-697 directly interacted with $\mathrm{P}$-selectin in a similar way, which verifies the rationality of the drug design of THCMA. In vitro competitive binding assays show that THCMA competitively inhibited the binding of P-selectin with ligand PSGL1 (Figure 2H). The in vitro inhibitory effect of THCMA on P-selectin 
was comparable to PSI-697 at $25 \mu \mathrm{M}$, which is in accordance with the results of molecular docking and UV spectra. However, because of its improved solubility, THCMA achieved significantly higher inhibition at $100 \mu \mathrm{M}$. In vivo downregulation of sP-selectin levels in arterial thrombosis rats, venous thrombosis rats, S180 mice, and ear-edema mice also support the P-selectin inhibitory effect of THCMA (Figure 8A-D). Results from these three experiments confirmed that our aim of designing THCMA as a new small-molecule P-selectin inhibitor had been achieved.

\section{Nanoring Structure Supports THCMA as a Nanomedicine}

Small molecule nanomedicines are directly assembled from pharmaceutical molecules with or without minimum excipients, which can largely improve drug-delivery efficiency and biosafety. ${ }^{48}$ TEM and SEM of THCMA (Figure 4) show that THCMA self-assembled into nanorings about $100 \mathrm{~nm}$ in diameter. The Tyndall effect, $\zeta$-potential, and particle-size tests (Figure 5) also confirmed that THCMA functioned as a stable small-molecule nanomedicine at various concentrations in both a neutral environment $(\mathrm{pH} \mathrm{7)}$ and an acidic environment like gastric fluid ( $\mathrm{pH} 2)$. The mechanism of the self-assembly of nanorings was proposed according to the results of FT-ICR-MS, NOESY $2 \mathrm{D}^{1} \mathrm{H}$ NMR (Figure 3) and the morphology of THCMA on TEM and SEM. Amphiphilic organic molecules THCMA self-assembled into a bilayer nanoring with the lipophilic parts exposed to an aqueous environment (Figure 4E). The formation of THCMA nanomedicine could help to improve its drug-delivery efficiency. These results indicate that our aim of designing THCMA as an amphiphile to form nanomedicine had been achieved.

\section{THCMA Effectively Inhibits Thrombosis, Inflammation, and Tumor Growth}

$\mathrm{P}$-selectin is considered a promising therapeutic target for antithrombosis and anti-inflammation drugs. The blockade of P-selectin has also been proved to inhibit tumor growth and metastasis in mice. ${ }^{8}$ Compared to the oral P-selectin inhibitor PSI-697, the new small-molecule P-selectin inhibitor THCMA exhibited significantly improved anti-arterial thrombus, anti-venous thrombus, anti-inflammation, and antitumor activity. Its oral anti-arterial and anti-venous thrombus activity was >100-fold that of PSI-697 (Figure 6A and B), oral anti-inflammation activity greater than tenfold that of PSI-697 (Figure 7A), and oral antitumor activity significantly better than PSI-697 (Figure 7B) THCMA possesses similar pharmacophores to PSI-697. The improvement in activity could be related to its good solubility. The self-assembly of THCMA into nanomedicine may also have contributed to the largely enhanced in vivo activity by improving drug-delivery efficiency.

In vivo results demonstrated that THCMA was highly potent in inhibiting venous thrombosis. Inhibition of venous thrombosis occurred at a dose that produced no significant changes in TT, PT, APTT or Fib and no prolonged tailbleeding time (Figure 6C and D). Bleeding and coagulation disorders are the major risks of warfarin. These results suggest that THCMA has the potential to be developed as an alternative to warfarin as an anti-venous thrombosis agent. THCMA nanoparticles were found on platelet surfaces with AFM (Figure 9C-E). THCMA exhibited significantly enhanced anti-arterial thrombosis activity and anti-platelet aggregation activity over PSI-697 (Figure 6A and F). The mechanism of THCMA's anti-arterial thrombosis activity could be related to its antiplatelet activity.

THCMA exhibited slightly more enhancement of antiinflammation and antitumor activity than PSI-697. The mechanism of the anti-inflammation activity of THCMA could be related to the downregulation of the inflammatory mediator TNF $\alpha$ in animal models (Figure 8E). The antitumor activity of THCMA was comparable to Dox. Moreover, THCMA exhibited no systemic toxicity, while Dox does. Venous thromboembolism is the second-most prevalent cause of death in cancer patients. ${ }^{49}$ Since THCMA possesses inhibitory effects on both venous thrombosis and tumor proliferation, it has the potential to be developed into a dualfunction drug treating cancer patients associated with venous thrombosis.

\section{Conclusion}

A new small-molecule P-selectin inhibitor - THCMA was successfully designed as a nanomedicine, showing largely enhanced solubility and oral efficacy over the clinical trial drug PSI-697. Our results suggest that THCMA selfassembles into nanorings of approximately $100 \mathrm{~nm}$ in diameter. THCMA's water solubility was about 1,030-fold that of PSI-697, oral efficacy 100-fold that of PSI-697 in inhibiting arterial and venous thrombosis, and tenfold that of PSI697 in inhibiting inflammation. Furthermore, unlike warfarin, THCMA inhibited venous thrombosis without coagulation disorders and bleeding risk. More interestingly, THCMA possesses comparable antitumor activity to Dox without causing systemic chemotherapy toxicity. THCMA has the 
potential to be developed as a therapeutic agent for the oral treatment of arterial thrombosis, venous thrombosis, inflammation, and cancer-associated thrombosis.

\section{Acknowledgments}

This work was financially supported by the Scientific Research Program of Beijing Municipal Education Commission (KM202110025024) and Funding for Training Excellent Talents in Beijing and Scientific Research. The authors thank Professor Zhao Ming and Professor Peng Shiqi for professional suggestions.

\section{Disclosure}

The authors declare that there are no conflicts of interest in this work.

\section{References}

1. Neri T, Nieri D, Celi A. P-selectin blockade in COVID-19-related ARDS. Am J Physiol Lung Cell Mol Physiol. 2020;318(6):L1237L1238. doi:10.1152/ajplung.00202.2020

2. Tao DL, Yunga ST, Williams CD, McCarty OJT. Aspirin and antiplatelet treatments in cancer. Blood. 2021;137(23):3201-3211. doi:10.1182/blood.2019003977

3. Pereira JL, Cavaco P, da Silva RCG, et al. P-selectin glycoprotein ligand 1 promotes $\mathrm{T}$ cell lymphoma development and dissemination. Transl Oncol. 2021;14(8):101125. doi:10.1016/j.tranon.2021.101125

4. Lu Z, Long Y, Wang Y, et al. Phenylboronic acid modified nanoparticles simultaneously target pancreatic cancer and its metastasis and alleviate immunosuppression. Eur $J$ Pharm Biopharm. 2021;165:164-173. doi:10.1016/j.ejpb.2021.05.014

5. Rossaint J, Thomas K, Mersmann S, et al. Platelets orchestrate the resolution of pulmonary inflammation in mice by $\mathrm{T}$ reg cell repositioning and macrophage education. Platelets orchestrate the resolution of pulmonary inflammation in mice by $\mathrm{T}$ reg cell repositioning and macrophage education. $J$ Exp Med. 2021;218(7):e20201353. doi:10.1084/jem.20201353

6. Schutzman LM, Rigor RR, Lin YJ, et al. P-selectin antibody treatment after blunt thoracic trauma prevents early pulmonary arterial thrombosis without changes in viscoelastic measurements of coagulation. J Trauma Acute Care Surg. 2021;90(6):1032-1039. doi:10.1097/TA.0000000000003162

7. Wong DJ, Park DD, Park S, et al. A PSGL-1 glycomimetic reduces thrombus burden without affecting hemostasis. Blood. 2021;2020009428. doi:10.1182/blood.2020009428

8. Nasti TH, Bullard DC, Yusuf N. P-selectin enhances growth and metastasis of mouse mammary tumors by promoting regulatory $\mathrm{T}$ cell infiltration into the tumors. Life Sci. 2015;131:11-18. doi:10.1016/j.lfs.2015.02.025

9. Sanchez-Lopez V, Gao L, Ferrer-Galvan M, et al. Differential biomarker profiles between unprovoked venous thromboembolism and cancer. Ann Med. 2020;52(6):310-320. doi:10.1080/ 07853890.2020 .1779956

10. Fabricius H, Starzonek S, Lange T. The role of platelet cell surface P-selectin for the direct platelet-tumor cell contact during metastasis formation in human tumors. Front Oncol. 2021;318(6):L1237-L1238.

11. Starzonek S, Maar H, Labitzky V, et al. Systematic analysis of the human tumor cell binding to human vs. murine E- and P-selectin under static vs. dynamic conditions. Glycobiology. 2020;30 (9):695-709. doi:10.1093/glycob/cwaa019
12. Geng X, Mihaila R, Yuan Y, et al. Inclacumab, a fully human anti-p-selectin antibody, directly binds to PSGL-1 binding region and demonstrates robust and durable inhibition of cell adhesion. Blood. 2020;136(Supplement 1):10-11. doi:10.1182/blood-2020-140530

13. Blair HA. Crizanlizumab: first approval. Drugs. 2020;80(1):79-84. doi:10.1007/s40265-019-01254-2

14. Krishnamurthy VR, Sardar MYR, Ying Y, et al. Glycopeptide analogues of PSGL-1 inhibit P-selectin in vitro and in vivo. Nat Commun. 2015;6(1):6387. doi:10.1038/ncomms7387

15. Tammara BK, Ryan K, Plotka A, et al. Effect of renal or hepatic impairment on the pharmacokinetics, safety, and tolerability of intravenous rivipansel. Life Sci. 2020;9(8):918-928.

16. Watz H, Bock D, Meyer M, et al. Inhaled pan-selectin antagonist bimosiamose attenuates airway inflammation in COPD. Pulm Pharmacol Ther. 2013;26(2):265-270. doi:10.1016/j.pupt.2012.12.003

17. Japp AG, Chelliah R, Tattersall L, et al. Effect of PSI-697, a novel P-selectin inhibitor, on platelet-monocyte aggregate formation in humans. J Am Heart Assoc. 2013;2(1):e006007. doi:10.1161/ JAHA. 112.006007

18. Alenazy FO, Thomas MR. Novel antiplatelet targets in the treatment of acute coronary syndromes. Platelets. 2021;32(1):15-28. doi:10.1080/09537104.2020.1763731

19. Aydt E, Wolff G. Development of synthetic pan-selectin antagonists: a new treatment strategy for chronic inflammation in asthma. Pathobiology. 2002;70(5):297-301. doi:10.1159/000070746

20. Bedard PW, Clerin V, Sushkova N, et al. Characterization of the novel P-selectin inhibitor PSI-697 2-(4-chlorobenzyl)-3-hydroxy7,8,9,10-tetrahydrobenzo $\mathrm{h}$ quinoline-4-carboxylic acid in vitro and in rodent models of vascular inflammation and thrombosis. $J$ Pharmacol Exp Ther. 2008;324(2):497-506. doi:10.1124/ jpet.107.128124

21. Myers DD Jr., Henke PK, Bedard PW, et al. Treatment with an oral small molecule inhibitor of P selectin (PSI-697) decreases vein wall injury in a rat stenosis model of venous thrombosis. J Vasc Surg. 2006;44(3):625-632. doi:10.1016/j.jvs.2006.05.021

22. Krishnamurthy VR, Dougherty A, Kamat M, Song X, Cummings RD, Chaikof EL. Synthesis of an Fmoc-threonine bearing core-2 glycan: a building block for PSGL-1 via Fmoc-assisted solid-phase peptide synthesis. Carbohydr Res. 2010;345 (11):1541-1547. doi:10.1016/j.carres.2010.05.004

23. Baumann K, Kowalczyk D, Kunz H. Total synthesis of the glycopeptide recognition domain of the P-selectin glycoprotein ligand 1. Angew Chem Int Ed Engl. 2008;47(18):3445-3449. doi:10.1002/ anie. 200705762

24. Leppanen A, Yago T, Otto VI, McEver RP, Cummings RD. Model glycosulfopeptides from P-selectin glycoprotein ligand-1 require tyrosine sulfation and a core 2-branched O-glycan to bind to L-selectin. $J$ Biol Chem. 2003;278(29):26391-26400. doi:10.1074/jbc.M303551200

25. Huang A, Moretto A, Janz K, et al. Discovery of 2-1-(4-chlorophenyl)cyclopropyl -3-hydroxy-8-(trifluoromethyl)quinoline -4-carboxylic acid (PSI-421), a P-selectin inhibitor with improved pharmacokinetic properties and oral efficacy in models of vascular injury. J Med Chem. 2010;53(16):6003-6017. doi:10.1021/ jm9013696

26. Xu X, Wang Y, Wu J, et al. ATIQCTPC: a nanomedicine capable of targeting tumor and blocking thrombosis in vivo. Int $J$ Nanomedicine. 2017;12:4415-4431. doi:10.2147/IJN.S129989

27. Wu J, Zhao M, Wang Y, et al. N-(3-hydroxymethyl-beta-carboline -1-yl-ethyl-2-yl)-L-Phe: development toward a nanoscaled antitumor drug capable of treating complicated thrombosis and inflammation. Drug Des Devel Ther. 2017;11:225-239. doi:10.2147/DDDT. S123919

28. Wu J, Zhao M, Wang Y, et al. A novel lead of P-selectin inhibitor: discovery, synthesis, bioassays and action mechanism. Bioorg Med Chem Lett. 2016;26(19):4631-4636. doi:10.1016/j.bmcl.2016.08.061 
29. $\mathrm{Xu} \mathrm{W}$, Zhao M, Wang $\mathrm{Y}$, et al. Design, synthesis, and in vivo evaluations of benzyl N-omega-nitro-N-alpha-(9H-pyrido 3,4-b indole-3-carbonyl)- L-argininate as an apoptosis inducer capable of decreasing the serum concentration of P-selectin. MedChemComm. 2016;7(9):1730-1737. doi:10.1039/C6MD00215C

30. Zhang X, Zhang Y, Wang Y, et al. Modifying ICCA with Trp-Phe-Phe to enhance in vivo activity and form nano-medicine. Int J Nanomedicine. 2020;15:465-481. doi:10.2147/IJN.S229856

31. Wu J, Zhu H, Yang G, et al. Design and synthesis of nanoscaled IQCA-TAVV as a delivery system capable of antiplatelet activation, targeting arterial thrombus and releasing IQCA. Int J Nanomedicine. 2018;13:1139-1158. doi:10.2147/IJN.S150205

32. Zhu H, Wang Y, Song C, et al. Docking of THPDTPI: to explore $\mathrm{P}$-selectin as a common target of anti-tumor, anti-thrombotic and anti-inflammatory agent. Oncotarget. 2018;9(1):268-281. doi:10.18632/oncotarget.19374

33. Zhao S, Li Z, Huang F, et al. Nano-scaled MTCA-KKV: for targeting thrombus, releasing pharmacophores, inhibiting thrombosis and dissolving blood clots in vivo. Int J Nanomedicine. 2019;14:4817-4831. doi:10.2147/IJN.S206294

34. Weitz-Schmidt G, Gong KW, Wong CH. Selectin/glycoconjugate binding assays for the identification and optimization of selectin antagonists. Anal Biochem. 1999;273(1):81-88. doi:10.1006/ abio. 1999.4180

35. Wu J, Zhu H, Yang G, et al. IQCA-TAVV: to explore the effect of P-selectin, GPIIb/ IIIa,IL-2, IL-6 and IL-8 on deep venous thrombosis. Oncotarget. 2017;8(53):91391-91401. doi:10.18632/ oncotarget. 20588

36. Wu J, Zhu H, Zhao M, et al. IQCA-TASS: a nano-scaled P-selectin inhibitor capable of targeting thrombus and releasing IQCA/ TARGD(S)S in vivo. $J$ Mater Chem B. 2017;5(5):917-927. doi:10.1039/C6TB02705A

37. Borsig L, Vlodavsky I, Ishai-Michaeli R, Torri G, Vismara E. Sulfated hexasaccharides attenuate metastasis by inhibition of P-selectin and heparanase. Neoplasia. 2011;13(5):445-452. doi:10.1593/neo.101734

38. Wang Q, Chen J, Wang D, et al. Rapid hemostatic biomaterial from a natural bath sponge skeleton. Mar Drugs. 2021;19(4):220. doi: $10.3390 / \mathrm{md} 19040220$

39. Du H, Wu Y, Wu H, Li F. Effect of ozone pretreatment on characteristics of dissolved organic matter formed in aerobic and anaerobic digestion of waste-activated sludge. Environ Sci Pollut Res Int. 2021;28(3):2779-2790. doi:10.1007/s11356-020-10596-4
40. Zheng J, Fan R, Wu H, et al. Directed self-assembly of herbal small molecules into sustained release hydrogels for treating neural inflammation. Nat Commun. 2019;10(1):1604. doi:10.1038/s41467019-09601-3

41. Yadav S, Sharma AK, Kumar P. Self-assembly for therapeutic delivery. Front Bioeng Biotechnol. 2020;8(127). doi:10.3389/ fbioe. 2020.00127

42. Costa J, Araujo A. Cancer-related venous thromboembolism: from pathogenesis to risk assessment. Semin Thromb Hemost. 2021. doi:10.1055/s-0040-1718926

43. Karsli E, Sabirli R, Altintas E, et al. Soluble P-selectin as a potential diagnostic and prognostic biomarker for COVID-19 disease: a case-control study. Life Sci. 2021;277:119634. doi:10.1016/j. 1fs.2021.119634

44. Navi BB, Sherman CP, Genova R, et al. Mechanisms of ischemic stroke in patients with cancer: a Prospective Study. Ann Neurol. 2021;90(1):159-169. doi:10.1002/ana.26129

45. Kaila N, Janz K, Huang A, et al. 2-(4-chlorobenzyl)-3-hydroxy7,8,9,10-tetrahydrobenzo $\mathrm{H}$ quinoline-4-carb oxylic acid (PSI-697): identification of a clinical candidate from the quinoline salicylic acid series of P-selectin antagonists. J Med Chem. 2007;50(1):40-64. doi:10.1021/jm060631p

46. Clerin V, Resmini C, Darby A, et al. WAY-197697, a P-selectin antagonist, reduces atherosclerosis and intimal hyperplasia in animal models of vascular disease. Circulation. 2004;110(17):177.

47. Myers DD Jr., Wrobleski SK, Longo C, et al. Resolution of venous thrombosis using a novel oral small-molecule inhibitor of P-selectin (PSI-697) without anticoagulation. Thromb Haemost. 2007;97 (3):400-407. doi:10.1160/TH06-11-0658

48. Xue X, Lindstrom A, Qu H, Li Y. Recent advances on small-molecule nanomedicines for cancer treatment. Wiley Interdiscip Rev Nanomed Nanobiotechnol. 2020;12(3):e1607. doi:10.1002/wnan. 1607

49. Gurizzan C, Roca E, Faggiano A, et al. Rate of venous thromboembolism and atrial fibrillation in a real-world case series of advanced cancer patients: the CaTEV Study. J Cardiovasc Med. 2021;22 (6):444-452. doi:10.2459/JCM.0000000000001124
International Journal of Nanomedicine

\section{Publish your work in this journal}

The International Journal of Nanomedicine is an international, peerreviewed journal focusing on the application of nanotechnology in diagnostics, therapeutics, and drug delivery systems throughout the biomedical field. This journal is indexed on PubMed Central, MedLine, CAS, SciSearch ${ }^{\circledR}$, Current Contents ${ }^{\circledR} /$ Clinical Medicine,
Journal Citation Reports/Science Edition, EMBase, Scopus and the Elsevier Bibliographic databases. The manuscript management system is completely online and includes a very quick and fair peer-review system, which is all easy to use. Visit http://www.dovepress.com/ testimonials.php to read real quotes from published authors. 